\title{
Effects of winter and summer-time irrigation over Gangetic Plain on the mean and intra-seasonal variability of Indian summer monsoon
}

\author{
Shubhi Agrawal ${ }^{1,2,3}$ (D) Arindam Chakraborty ${ }^{1,2} \cdot$ Nirupam Karmakar $^{4} \cdot$ Simon Moulds $^{5} \cdot$ Ana Mijic $^{6}$. \\ Wouter Buytaert ${ }^{6}$
}

Received: 27 March 2018 / Accepted: 18 February 2019

(c) Springer-Verlag GmbH Germany, part of Springer Nature 2019

\begin{abstract}
The decreasing trend in rainfall in the last few decades over the Indo-Gangetic Plains of northern India as observed in groundbased observations puts increasing stress on groundwater because irrigation uses up to $70 \%$ of freshwater resources. In this work, we have analyzed the effects of extensive irrigation over the Gangetic Plains on the seasonal mean and intra-seasonal variability of the Indian summer monsoon, using a general circulation model and a very high-resolution soil moisture dataset created using extensive field observations in a state-of-the-art hydrological model. We find that the winter-time (NovemberMarch) irrigation has a positive feedback on the Indian summer monsoon through large scale circulation changes. These changes are analogous to a positive North Atlantic Oscillation (NAO) phase during winter months. The effects of the positive NAO phase persist from winter to spring through widespread changes in surface conditions over western and central Asia, which makes the pre-monsoon conditions suitable for a subsequent good monsoon over India. Winter-time irrigation also resulted in a reduction of low frequency intra-seasonal variability over the Indian region during the monsoon season. However, when irrigation is practiced throughout the year, a decrease in June-September precipitation over the Gangetic Plains, significant at $95 \%$ level, is noted as compared to the no-irrigation scenario. This decrease is attributed to the increase in local soil moisture due to irrigation, which results in a southward shift of the moisture convergence zone during the active phase of monsoon, decreasing its mean and intraseasonal variability. Interestingly, these changes show a remarkable similarity to the long-term trend in observed rainfall spatial pattern and low-frequency variability. Our results suggest that with a decline in the mean summer precipitation and stressed groundwater resources in the Gangetic Plains, the water crisis could exacerbate, with irrigation having a weakening effect on the regional monsoon.
\end{abstract}

Keywords Irrigation $\cdot$ Indian monsoon $\cdot$ Intraseasonal variability $\cdot$ North Atlantic Oscillations

Electronic supplementary material The online version of this article (https://doi.org/10.1007/s00382-019-04691-7) contains supplementary material, which is available to authorized users.

Shubhi Agrawal

sagrawal2@albany.edu

1 Centre for Atmospheric and Oceanic Sciences, Indian Institute of Science, Bangalore, India

2 Divecha Centre for Climate Change, Indian Institute of Science, Bangalore, India

3 Atmospheric Sciences Research Center, University at Albany, State University of New York, Albany, NY, USA

4 Earth, Ocean and Atmospheric Science Department, Florida State University, Tallahassee, FL, USA

5 Centre for Water Systems, University of Exeter, Exeter, UK

6 Department of Civil and Environmental Engineering, Imperial College London, London, UK

\section{Introduction}

A large ratio of the Indian population is directly and strongly affected by the vagaries of the Indian summer monsoon (ISM) (Saha et al. 1979; Gadgil and Gadgil 2006; Turner and Annamalai 2012). In the changing climatic conditions, it is crucial to understand the impact of anthropogenic activities on the monsoon and its variability. Many recent studies reported significant changes in several characteristics of ISM during the last few decades. These include a decrease in seasonal (June-September: JJAS) mean rainfall (Naidu et al. 2010; Kulkarni 2012; Naidu et al. 2015; Guhathakurta and Revadekar 2017), decrease in the variance of its lowfrequency intraseasonal oscillation (ISO) (Karmakar et al. 2015), decrease in the number of monsoon disturbances (Patwardhan and Bhalme 2001; Pattanaik 2007; Vishnu 
et al. 2016), an increase in the frequency of extreme rainfall events (Goswami et al. 2006; Rajeevan et al. 2008; Krishnamurthy et al. 2009), especially during the break phase of ISO (Karmakar et al. 2015). It is demonstrated that some of these observed changes are connected through a common mechanism (Karmakar et al. 2017b).

The climate driver for the decrease in seasonal mean rainfall of ISM has been debated in the literature. Sinha et al. (2015) showed that the reduction in monsoon rainfall since the 1950s is a part of multidecadal oscillations. However, several other studies attribute this to anthropogenic factors and changes in sea surface temperature (SST) over different ocean basins. Meehl et al. (2008) and Bollasina et al. (2011) showed a decrease in monsoonal rainfall over the India region due to aerosols. However, Chakraborty et al. (2014) showed the role of heating effects of aerosols (mainly black carbon) in increasing precipitation in June-July, mainly due to more conducive pre-monsoon conditions. Though the net effect of aerosols on the Indian monsoon can be argued upon, but definitely, aerosols remain an important anthropogenic forcing in addition to other factors. More recently, Roxy et al. (2015) related the weakening of the Indian monsoon to warming over the equatorial Indian Ocean, but also discuss the possibility of a reversed feedback mechanism between them. Paul et al. (2016) studied the effects of land use/land cover change on the Indian monsoon, related to the conversion of forest to cropland, and attributed the reduction in rainfall over central India to decrease in evapotranspiration. But the major issue with this study is that it did not consider irrigation in addition to land use change, which can completely transform the land surface conditions and result in an increase in evaporation. Many studies (Douglas et al. 2006, 2009; Sacks et al. 2009; Puma and Cook 2010) showed that irrigation increases the local evaporation. Additionally, Tuinenburg et al. (2014) and Cook et al. (2015) attributed the decrease in summer precipitation over northern India to surface cooling due to irrigation.

The decreasing trend in rainfall in the last few decades over the Gangetic Plains of northern India poses a serious threat to the water sufficiency and agricultural productivity over the region, which is also one of the most densely populated regions of the world. The situation is further aggravated by swiftly dwindling groundwater resources in certain pockets (Singh 2000; Rodell et al. 2009). Irrigation utilizes up to $70 \%$ of freshwater resources (Siebert et al. 2010) and the demand is deemed to increase (Fraiture and Wichelns 2010) in order to increase the agricultural productivity to feed the ever-increasing population.

Intensification of irrigation over the Gangetic Plains in the recent decades can have a strong impact on the regional climate, as well as have global implications. Two major crop seasons exist in India. The 'Rabi' season lasts from October-March (winters) when the climatology is very dry and the 'Kharif' season lasts from June-October, with the crop sowing period aligned with the monsoon onset phase. Irrigation can result in cooling of surface temperature due to latent heat loss and affect the near-surface conditions (Sacks et al. 2009; Douglas et al. 2009; Puma and Cook 2010; Thiery et al. 2017). The importance of land-atmosphere coupling over the Gangetic Plains has already been established in previous studies (Koster et al. 2004; Agrawal and Chakraborty 2016). Agrawal and Chakraborty (2016) demonstrated a negative coupling between the local soil moisture and precipitation over the Gangetic Plains for the monsoon season. Lee et al. (2009) and Niyogi et al. (2010) used satellite-based normalized difference vegetation index (NDVI) to analyze the effects of pre-monsoon irrigational activities and found a negative correlation between March-May NDVI values and July mean precipitation over central and southern India. Douglas et al. (2009) examined impacts of irrigation on the land surface conditions over India using a regional model and showed an increase in latent heat flux over irrigated regions. Puma and Cook (2010) used a general circulation model to study the effects of irrigation on large scale and reported a decrease in precipitation over the south-eastern region of India due to irrigation, while Tuinenburg et al. (2014) showed a decrease in local precipitation over the eastern Gangetic Plains due to irrigation and noted a westward shift in precipitation. Similarly, Shukla et al. (2014) reported a weakening of the South Asian summer monsoon circulation as well as a decrease in its variability, due to intensification of irrigation and increased green house gas forcing, and attributed it to a decreased land-sea contrast. Cook et al. (2015) pointed out that over most of the irrigated regions globally, irrigation causes surface cooling and increases cloud cover, resulting in a regional increase in precipitation. Except, over some regions in Asia the surface cooling results in weakening of the monsoon circulations and consequently reducing precipitation. However, these studies (Sacks et al. 2009; Puma and Cook 2010; Tuinenburg et al. 2014; Shukla et al. 2014; Cook et al. 2015) which have examined the role of irrigation using global circulation models have done so at a coarser resolution (between $1.5^{\circ}$ and $2.5^{\circ}$ ). There is a scope for a study focussed on the Indian region to derive a mechanistic understanding of the role of regional irrigation in modulating the Indian monsoon and its intraseasonal variability, India being a hotspot for land-atmosphere coupling (Koster et al. 2004). Also, Lee et al. (2011) showed that irrigation can cause anomalies in global atmospheric circulation and thus it could be of interest to examine this effect for irrigation over the Gangetic Plains.

In this paper, we have analyzed the effects of the extensive irrigation over the Gangetic Plains on the seasonal mean and intra-seasonal variability of the Indian summer monsoon, using a state-of-the-art general circulation model, run at a reasonably high resolution (nearly $0.5^{\circ}$ ) 
and a high-resolution soil moisture dataset. This high-resolution dataset of soil moisture over the Gangetic Plains from Moulds (2016) takes into account both land use/land cover change and irrigation activities, with inputs from field measurements and satellite data. Brief detail of this data set is covered in Sect. 2.1. These soil moisture fields are used to force the general circulation model which has a realistic land-atmosphere coupling. We have analyzed the effects of irrigation performed in winter months and summer months separately, as well as, when irrigation is carried out annually. Model, experiment setups, and methodology are described briefly in Sect. 2, followed by results and discussions in Sect. 3 and summary in Sect. 4.

\section{Data, model and methodology}

\subsection{JULES dataset}

A very high-resolution dataset of soil moisture over Gangetic Basin was generated using the Joint UK Land and Environment Simulator (JULES, version 2.2), which is a processbased land surface model. This soil moisture dataset is used in the experimental design of general circulation model. The dataset is briefly described in the supplementary material for the benefit of the reader and more details can be found in Moulds (2016).

The first set of soil moisture dataset (JUL_NOIRG), for the time period 1971-2005, takes into account the effects of land use/land cover (LULC) change, but irrigation is not considered. The second set of soil moisture dataset (JUL_IRG), for the same period 1971-2005, considers the effects of both LULC change and irrigational activities over the Gangetic Plains. These two historical soil moisture data sets are used to investigate the climatic impact of irrigation on the Indian monsoon, using a general circulation model (details to follow). Figure 1 shows the soil moisture dataset from JULES experiments. Data for the time-period 1982-2002 is used in this study. This time period is chosen because the difference between irrigation and no-irrigation scenarios is much higher during these recent decades as compared to the earlier period between 1971-1981. Figure 1a shows the difference of top layer (with a depth of $0.1 \mathrm{~m}$ ) soil moisture between irrigation (JUL_IRG) and no-irrigation (JUL_NOIRG) scenarios for the month of June-September (JJAS), which majorly represents Kharif crop season and also the summer monsoon season in India. The difference between the irrigation and no-irrigation scenarios is small and only noticeable over north-west India. Whereas, Fig. $1 b$ shows the same for winter months of November-February (NDJF), when
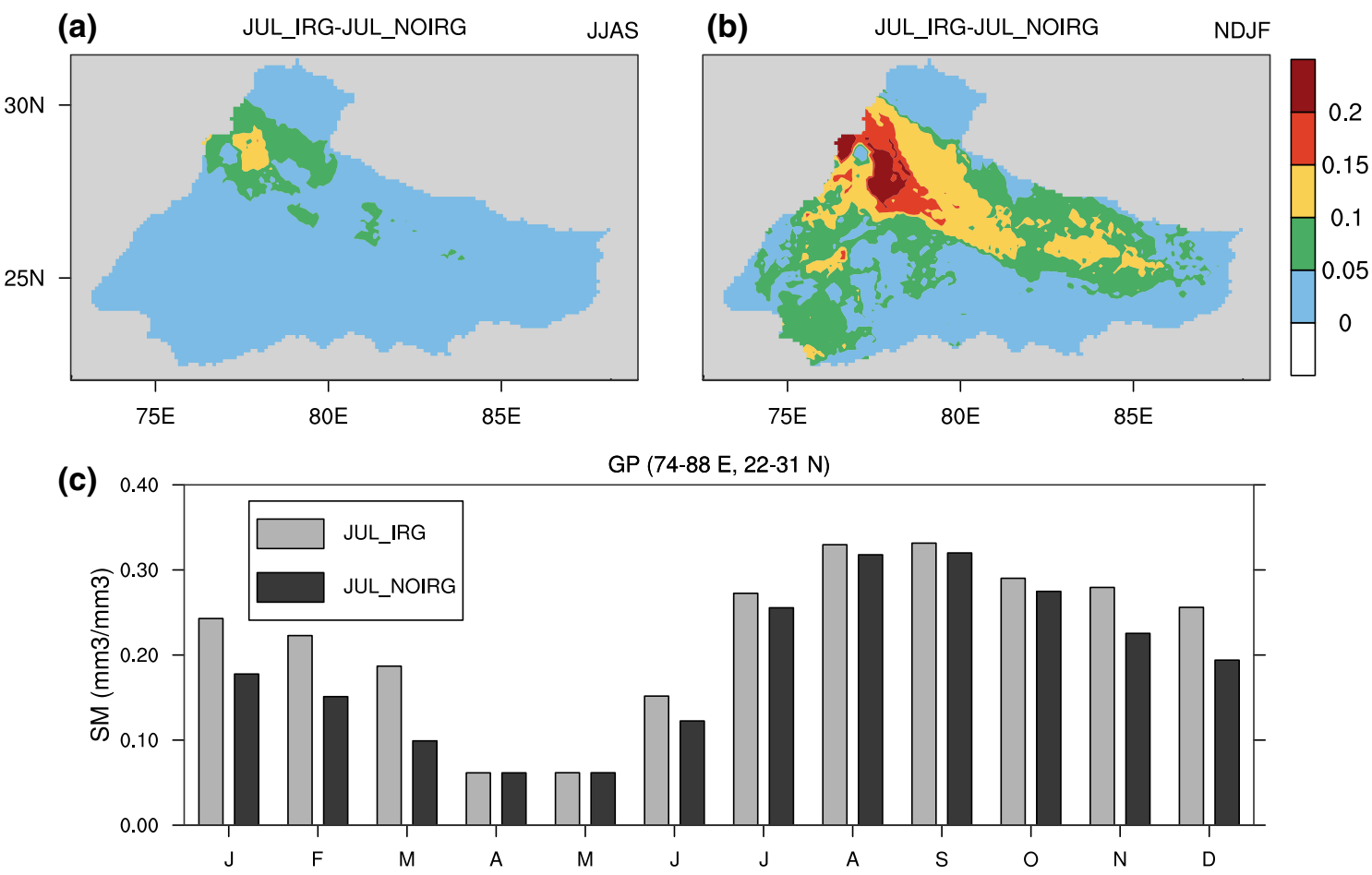

Fig. 1 Spatial difference of top layer $(0.1 \mathrm{~m})$ soil moisture values (in $\mathrm{mm}^{3} \mathrm{~mm}^{-3}$ ) between irrigation (JUL_IRG) and no-irrigation (JUL_ NOIRG) scenarios from JULES dataset for the month of a June-September (JJAS) and b November-February (NDJF). c Annual cycle of monthly mean surface soil moisture values $\left(\right.$ in $\mathrm{mm}^{3} \mathrm{~mm}^{-3}$ ) for JUL_ IRG and JUL_NOIRG, area averaged over Gangetic Basin $\left(74^{\circ}-88^{\circ} \mathrm{E}\right.$, $22^{\circ}-31^{\circ} \mathrm{N}$ ). JULES data for the time-period $1982-2002$ is used in this study 
extensive irrigation is done for the Rabi crops and significant differences can be noticed in surface soil moisture values throughout the Gangetic Plains, with prominent difference over the north-west region. This region with extensive irrigation mainly comprises of the states of Haryana and Punjab, which have a wide network of irrigation canals. Annual cycles of monthly mean soil moisture values for the top layer are shown for JUL_IRG and JUL_NOIRG scenarios, averaged over the Gangetic Basin $\left(74^{\circ}-88^{\circ} \mathrm{E}, 22^{\circ}-31^{\circ} \mathrm{N}\right.$, same as shown in $a$ ). Prominent differences in soil moisture are noticeable for the winter months (NDJF) over Gangetic Basin, whereas during JJAS difference is small, presumably due to less irrigational activity during monsoon season. These two monthly mean time series are used to modify the surface soil moisture in various model experiments, which offer a detailed perspective on the climatic impact of the intensified irrigation activities over the Gangetic Plains in the recent decades.

\subsection{Experiment setup details}

In this study, CESM 1.0.4 with coupled Community Atmospheric Model (CAM 5.1.1) and Community Land Model (CLM 4.0) is run with monthly climatological sea surface temperatures and prescribed sea-ice coverage as input. The CAM model is used with a finite-volume dynamical core with a grid resolution of $0.43^{\circ}$ (latitude) $\times 0.63^{\circ}$ (longitude) with a global domain. Details of this model have been described in Agrawal and Chakraborty (2016). Experiments conducted with the model configuration are explained here and listed in Table 1.

All atmospheric fields are allowed to evolve freely without any forcing. In the land model, top layer soil moisture, only over required domain $\left(74^{\circ}-88^{\circ} \mathrm{E}, 22^{\circ}-31^{\circ} \mathrm{N}\right)$, is gradually nudged towards the JULES monthly mean time series from either of the two scenarios as per the required experiment design, at each time step. The relaxation parameter for nudging is kept comparable to time-step of the model, in order to preserve the frequency characteristics of the variable (Telford et al. 2008; Jeuken et al. 1996) (For more details refer Section 2 and Figure S1 in the supplementary material). The water balance is maintained in the land model by adjusting the additional water with the aquifer. The nudging technique used here is similar to that demonstrated in Agrawal and Chakraborty (2016) (also Agrawal 2018) and has been briefly described in the Section 2 of the supplementary material. All the other land surface variables and also soil moisture outside the chosen domain are allowed to evolve freely.

Four experiments are conducted with different irrigation scenarios, using the same methodology. Ten years of data is generated for each experiment at a daily temporal resolution, with a model time-step of thirty minutes. The experiments and the main differences in them are as follows:

noIrrg: This experiment is the no irrigation case. In this experiment, top layer soil moisture over the required domain is gradually nudged towards the JULES monthly mean time series for no-irrigation scenario (JUL_NOIRG; described in Sect. 2.1) for all the months, that is from January to December. With this experiment, we achieve surface soil moisture values over the Gangetic Plains when irrigation was not prevalent over the region.

Irrg: This experiment is the annual irrigation case over the Gangetic Plains. It is conducted following the same approach, except that the values used to nudge the top layer are from the irrigation scenario of JULES dataset (JUL_IRG), and the nudging is from January through December.

winIrrg: In this experiment, the aim is to analyze the effect of winter-time irrigation alone on the Indian monsoon. Hence, JUL_IRG is used to nudge the top layer during the winter months from November to March. From April to October, JUL_NOIRG is used to nudge the top soil layer over the domain. To state simply, irrigation is restricted to the winter season only, over the desired domain, in order to analyze its effects independently.

jjasIrrg: This experiment is opposite of above experiment in its design, as the intention is to analyse the effect of summer-time irrigation alone on the Indian monsoon. Therefore, JUL_IRG is used to nudge the top layer during the summer months from June-September. For all the remaining months, JUL_NOIRG is used to nudge the top layer over domain. In short, irrigation is restricted to the summer months only, over the desired domain.
Table 1 List of experiments, abbreviations and brief descriptions

\begin{tabular}{lll}
\hline Experiment & Abbreviation & Description \\
\hline No irrigation & noIrrg & SM is nudged to no irrigation values over GP \\
Annual irrigation & Irrg & SM is nudged to irrigation values over GP all round the year \\
Winter irrigation & winIrrg & SM is nudged to irrigation values over GP from November \\
& & to March, and to no irrigation values during other months \\
Summer irrigation & jjasIrrg & SM is nudged to irrigation values over GP from June to \\
& & September, and to no irrigation values during other \\
& & months \\
\hline
\end{tabular}


The output is analyzed at daily timescale, 10-year ensemble means are presented.

\subsection{Observational dataset}

In-situ observational precipitation data at a spatial resolution of $1.0^{\circ} \times 1.0^{\circ}$ from India Meteorological Department (IMD; Rajeevan et al. 2006) for the period 1951-2013 has been used.

Additionally, precipitation data from TRMM-3B42 (Huffman et al. 2007), which is a satellite-based merged-infrared precipitation product, is used and is referred as TRMM. It is available at a temporal resolution of three-hourly and a spatial resolution of $0.25^{\circ} \times 0.25^{\circ}$. Daily data of horizontal winds from the ERA-Interim (Dee et al. 2011) at a spatial resolution of $0.75^{\circ} \times 0.75^{\circ}$ is used. Data for the time period 2000-2010 is used for these two products.

\subsection{Extraction of intra-seasonal oscillations}

The Indian monsoon is characterized by two dominant intraseasonal oscillatory modes- the low frequency oscillations (LF-ISO, 20-60 days time period) and the high frequency oscillations (HF-ISO, 10-20 days time period). Low frequency oscillations are related to the northward progression of cloud bands (Yasunari 1979; Sikka and Gadgil 1980; Krishnamurthy and Shukla 2007) and high frequency oscillations are related to the north-westward propagation of low pressure systems that generate over Bay of Bengal (Krishnamurti and Bhalme 1976; Murakami 1976; Chen and Chen 1993). These modes can be extracted from rainfall data using various data filtering techniques in frequency domain (Ghil et al. 2002). Here, we have used multichannel singular spectrum analysis (MSSA) technique, following Ghil et al. (2002) and Karmakar et al. (2017a), who have demonstrated the efficiency of this method for filtering climate data. The methodology used to filter out the intra-seasonal modes from precipitation data is described in the supplementary text. The reconstructed data (filtered precipitation data) in low frequency domain (20-60 days time-period) is referred as LF-ISO and has the units of $\mathrm{mm} \mathrm{day}^{-1}$, and that in high frequency domain (10-20 days time-period) is referred as HF-ISO (unit- mm day ${ }^{-1}$ ). In the analysis that follows, only June-September data is used.

\subsubsection{Determining the phase composites of ISOS}

The phase angle of an ISO cycle (LF-ISO or HF-ISO) at a particular grid point can be determined by the following equation (Karmakar et al. 2017a):

$\phi(t)=\operatorname{Arg}\left(Y^{\prime}(t)+i Y(t)\right)$ where $t$ denotes time, $Y(t)$ is the 122 days long (June-September) ISO (LF-ISO or HF-ISO) time series and (') indicates the time-derivative. $Y(t)$ is obtained by area averaging ISOs values (LF-ISO or HF-ISO) over the required domain (Gangetic Plains in this case; $76^{\circ}-88^{\circ} \mathrm{E}, 22^{\circ}-28^{\circ} \mathrm{N}$ ), for each year. $\operatorname{Arg}(z)$ represents the phase angle of a complex number $z=x+i y$. Thus, the phase angle of the ISO cycle, $\phi(\mathrm{t})$, is calculated at every $t$ each year and lies between $-\pi$ and $\pi$. Further, the phase plane is divided into 8 equal phase intervals between $-\pi$ and $\pi$, where

$$
\begin{aligned}
& \text { phase }(i)=(m-1) \pi / 4 \leq \phi(t)<(m) \pi / 4, \text { for } i=1,2,3, \\
& 4, m \text { varies as } m=1,2,3,4 \text {. And } \\
& \text { phase }(i)=(m) \pi / 4 \leq \phi(t)<(m+1) \pi / 4, \text { for } i=5,6,7, \\
& 8, m \text { varies as } m=-4,-3,-2,-1 .
\end{aligned}
$$

To create phase composites (Moron et al. 1998), all the occurrences of $Y(t)$ in a given phase are averaged, regardless of the amplitude.

Further, positive (active) phase of $Y(t)$ is recognized when $\pi / 6 \leq \phi(t) \leq 5 \pi / 6$ and negative (break) phase is recognized when $-5 \pi / 6 \leq \phi(t) \leq-\pi / 6$.

\section{Results and discussions}

\subsection{Effects of winter-time irrigation}

During the winter season, agricultural activities are possible only in the lower latitudes of Northern hemisphere, as extremely cold temperatures prevail in northern latitudes. The Gangetic Plains has a major crop season in winter months-Rabi when a staple food crop (wheat) is cultivated. Amount of irrigational water added to the soil is much higher in winters, compared to summertime irrigation, as winter is a very dry season. Hence, the effects of winter-time irrigation on summer monsoon over India at seasonal and intra-seasonal time scales are analyzed through an idealized experiment in which irrigation is considered only during winter months (November-March) and is compared to the no-irrigation case, noIrrg. We first present the observed monsoon climatology over the Indian region in Fig. 2a, which shows JJAS mean precipitation from TRMM observations and overlaid mean $850 \mathrm{hPa}$ winds from ERA-Interim reanalysis dataset, for the period 2000-2010. Figure $2 b$ shows the climatology of monsoonal precipitation from the noIrrg experiment, overlaid with mean winds at $850 \mathrm{hPa}$. The climatological features are very similar to the long term observations. The model simulates the precipitation over monsoon core zone reasonably well, but has strong bias along the Western Ghats, Himalayas and Myanmar coast. These biases have been reported in earlier studies as well (Meehl et al. 2012; Islam et al. 2013; Agrawal and Chakraborty 


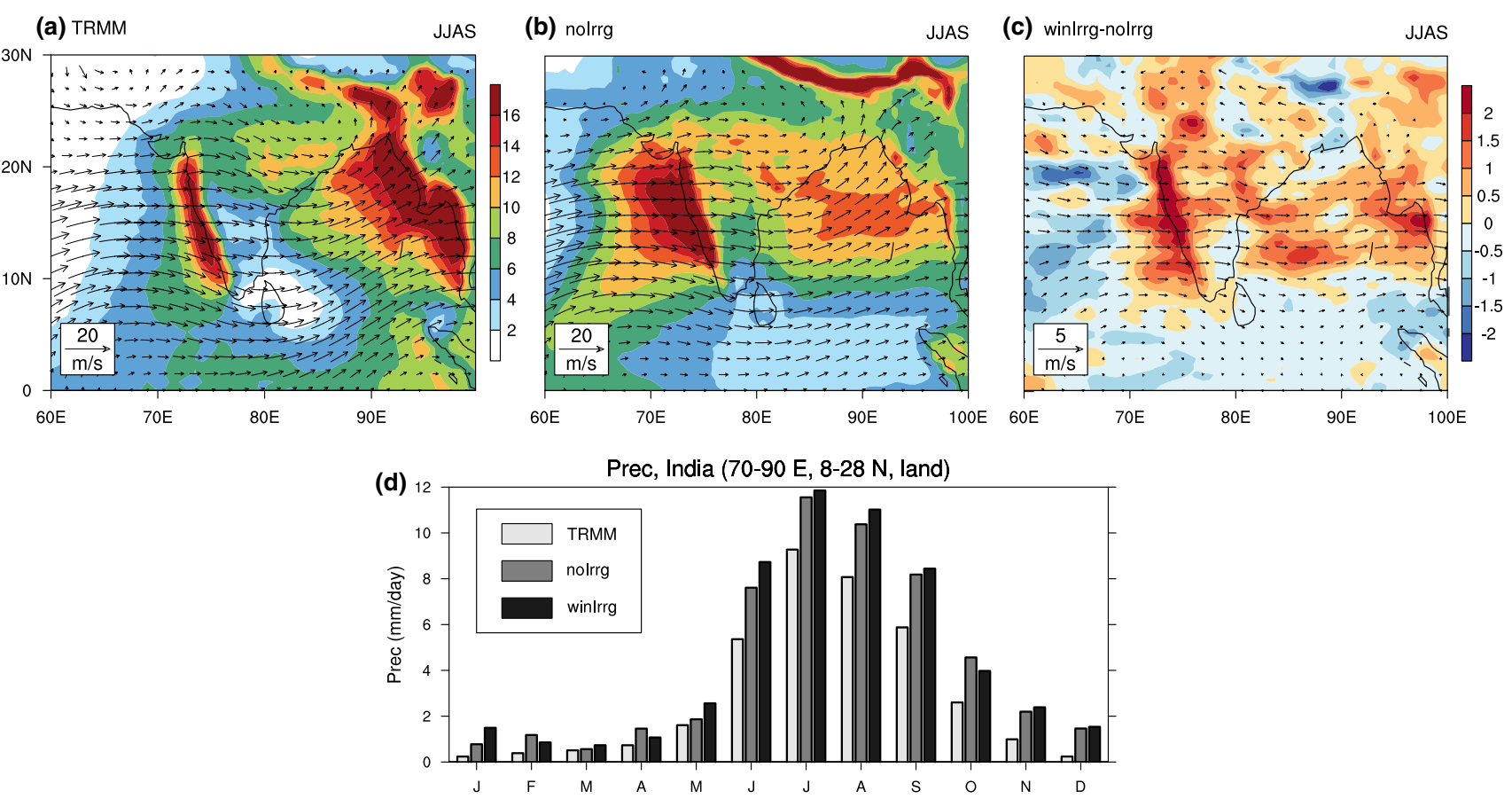

Fig. 2 a Spatial pattern of TRMM precipitation $\left(\mathrm{mm} \mathrm{day}^{-1}\right)$ and ERA-Interim $850 \mathrm{hPa}$ Winds $\left(\mathrm{m} \mathrm{s}^{-1}\right)$ during JJAS. b Spatial pattern of simulated precipitation $\left(\mathrm{mm} \mathrm{day}^{-1}\right)$ and $850 \mathrm{hPa}$ Winds $\left(\mathrm{m} \mathrm{s}^{-1}\right)$ during JJAS for noIrrg experiment. c Difference in winIrrg experi-

2016). The control simulation of the same model has been thoroughly compared with observations in a prior study by Agrawal and Chakraborty (2016). Figure 2c shows the difference between winIrrg and noIrrg, which shows the effect of winter-time irrigation on the Indian summer monsoon (June-September: JJAS). Statistical significance of the differences is checked using Student's t-test and the differences significant at $90 \%$ and $95 \%$ level are stippled using cross and stars respectively. It can be noted that in winIrrg, precipitation increases significantly over the Indian region and the adjoining Bay of Bengal and the monsoonal winds are also stronger over South Asia, as compared to noIrrg. Figure 2d shows the annual cycle of precipitation over the Indian land region $\left(70^{\circ}-90^{\circ} \mathrm{E}, 8^{\circ}-28^{\circ} \mathrm{N}\right)$ for TRMM, noIrrg and winIrrg. It can be again noted that the model simulates the annual cycle reasonably well, following it closely, with small overestimation in summer months. When comparing noIrrg and winIrrg experiments, precipitation increases during summer months and pre-monsoon month (May) in winIrrg experiment, and the increase is highest in June, the early phase of the monsoon season.

We further analyze the effects of winter-time irrigation on the intra-seasonal oscillations of the Indian summer monsoon, using MSSA technique to filter out the low (LF-ISO) and high (HF-ISO) frequency components from the seasonal precipitation. The technique is briefed ment with respect to noIrrg for the same, precipitation and $850 \mathrm{hPa}$ winds. Precipitation differences significant at $90 \%$ and $95 \%$ level are marked by cross and stars respectively. d Climatological annual cycles of rainfall from TRMM, noIrrg and winIrrg, averaged over Indian region $\left(8^{\circ}-28^{\circ} \mathrm{N}, 70^{\circ}-90^{\circ} \mathrm{E}\right.$, land part $)$

in Sect. 2.4. It is worthwhile to discuss here the model's ability to simulate the intraseasonal oscillations in low and high frequency range. The model is able to capture the two dominant modes of variability, that is the low frequency oscillation mode between 20 and 60 days time period and the high frequency oscillation mode between 10 and 20 days time period. However, the intensity of these oscillations are underestimated as compared to the observations (Figure S2). Earlier studies (Kang et al. 2002; Sabeerali et al. 2013; Karmakar et al. 2017b) on the same model (CAM) have also reported similar underestimation of the precipitation variance, nevertheless model captured the northward (Figure S9) and north-westward (Figure S10) propagations over the Indian region reasonably well. Nearly $16-22 \%$ of the total variance at intra-seasonal time-scale over the core monsoon region is contributed by LF-ISO and HF-ISO each (Figure S3), which can strongly influence the mean seasonal rainfall, thus emphasizing the importance of understanding the intra-seasonal oscillations in order to better understand the changes in mean seasonal rainfall. Figure 3 shows the difference between the precipitation variances of winIrrg and noIrrg, with differences significant at $90 \%$ and $95 \%$ level highlighted by cross and stars respectively. LF-ISO intensity (Fig. 3a) decreased considerably in the case of winIrrg as compared to noIrrg over the entire Indian region, and significantly over the head Bay of Bengal, western coast of 
(a) winlrrg-nolrrg

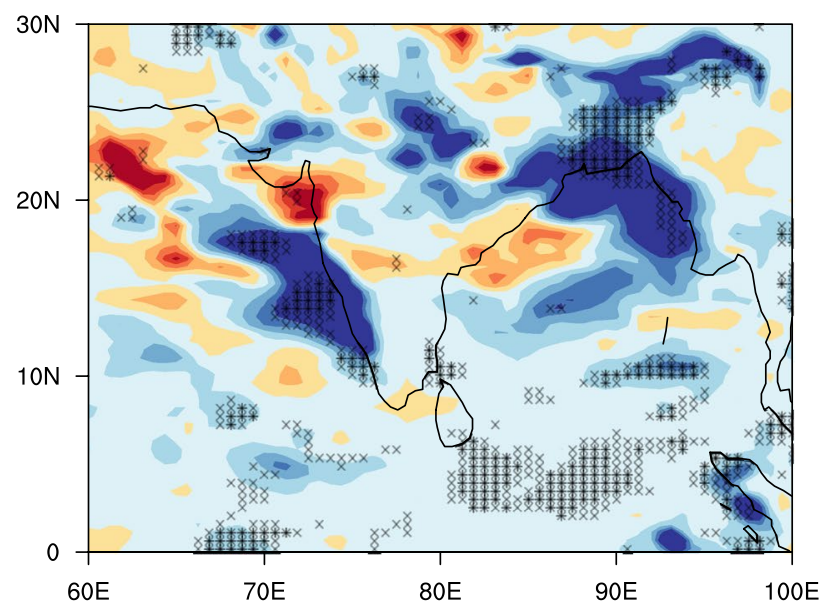

(b) winlrrg-nolrrg

HF-ISO

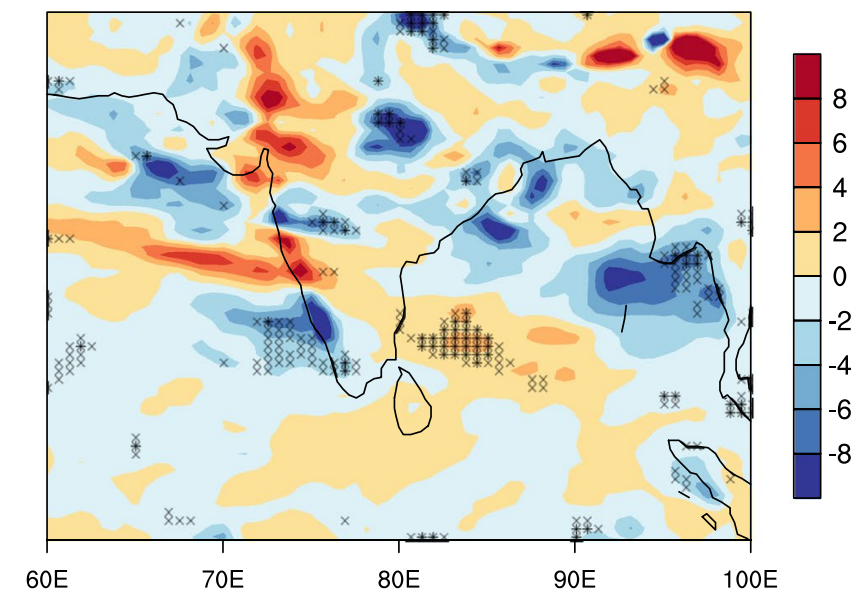

Fig. 3 Difference between the precipitation variance $\left(\mathrm{mm}^{2}\right.$ day ${ }^{-2}$ ) of winIrrg and noIrrg (winIrrg-noIrrg) during JJAS, in the two frequency domains-a LF-ISO, b HF-ISO. Differences significant at $90 \%$ and $95 \%$ level are marked by cross and stars respectively

India and the Gangetic Plains. On the contrary, we do not notice any significant and spatially homogeneous change in the HF-ISO intensity (Fig. 3b) in winIrrg as compared to noIrrg. Recall here that the mean seasonal precipitation increased over the Indian region in the case of winIrrg as compared to noIrrg and a few studies have reported such an inverse relationship between the low frequency intra-seasonal oscillations and seasonal mean precipitation over the core monsoon Indian region (Lawrence and Webster 2001; Karmakar et al. 2017a). We also found a negative correlation value of -0.48 between the mean summer rainfall over the Indian region and percent variance explained by LFISO, for the 10 model years in the noIrrg experiment (Figure S4). In essence, winter-time irrigation results in an increased summer-time precipitation and causes a decrease in the lowfrequency variability over the Indian region.

\subsubsection{Effects on the northern-hemisphere winters}

In order to understand the cause of the changes seen in the monsoonal precipitation in the case of winter irrigation with respect to no irrigation case, we start our analysis from the winter months, that is from January to March, when the irrigation is of a substantial amount. The left panel of Fig. 4 shows the difference of geopotential height at $850 \mathrm{hPa}$ between winIrrg and noIrrg in the months of January-February-March (abbreviated as JFM) in color contours, overlaid with the difference of air temperature at $900 \mathrm{hPa}$ in green colored line contours, with negative anomalies in dashed lines and positive anomalies in solid lines. Differences significant at $90 \%$ level in air temperature are hatched. Geopotential height increased over the Indian region in winIrrg, with a substantial increase between $30^{\circ}$ and $40^{\circ} \mathrm{N}$, indicating increased surface pressures. Climatologically this region experiences subsidence during these months and positive surface pressure anomalies signify increased subsidence along $30^{\circ} \mathrm{N}$. The increased geopotential height at $850 \mathrm{hPa}$ (surface pressure) can be attributed to surface cooling due to winter time irrigation and can also be noted from negative air temperature anomalies (dashed line contours) over central and northern India. Simultaneously, a decrease in geopotential can be noted near Madagascar, around $30^{\circ} \mathrm{S}$. This increases the north-south gradient in geopotential, which intensifies the low-level cross-equatorial flow of air from northern to southern hemisphere. This is also the direction of mean wind flow in boreal winters and thus increasing the convective activities in southern Hemisphere during southern summers. As a consequence, an intensification of the Hadley cell is noted from the vertical pressure velocities, shown in the right panel of Fig. 4. Difference of omega (vertical velocity in $\mathrm{Pa} \mathrm{s}^{-1}$ ) between winIrrg and noirrg, averaged over $70^{\circ}-90^{\circ} \mathrm{E}$, for January-March is shown, and it can be noted that subsidence (positive omega) increased strongly to the north of $20^{\circ} \mathrm{N}$ and convective activities (negative omega) increased near $30^{\circ} \mathrm{S}$. Differences significant at $90 \%$ level are marked by cross. Weak positive meridional wind anomaly at $200 \mathrm{hPa}$ is also noted for January-March in the winIrrg experiment over Indian region. These results are consistent with the findings of Wey et al. (2015).

It can be observed that the winter irrigation over northern India has a strong regional effect. Lee et al. (2011) have shown that irrigation can modulate global atmospheric circulation. Hence, next we examine the changes brought about by the winter irrigation at a global scale in the northern hemisphere winters. Figure 5a shows the difference in surface pressure (in $\mathrm{hPa}$ ) between winIrrg and noIrrg, for the 


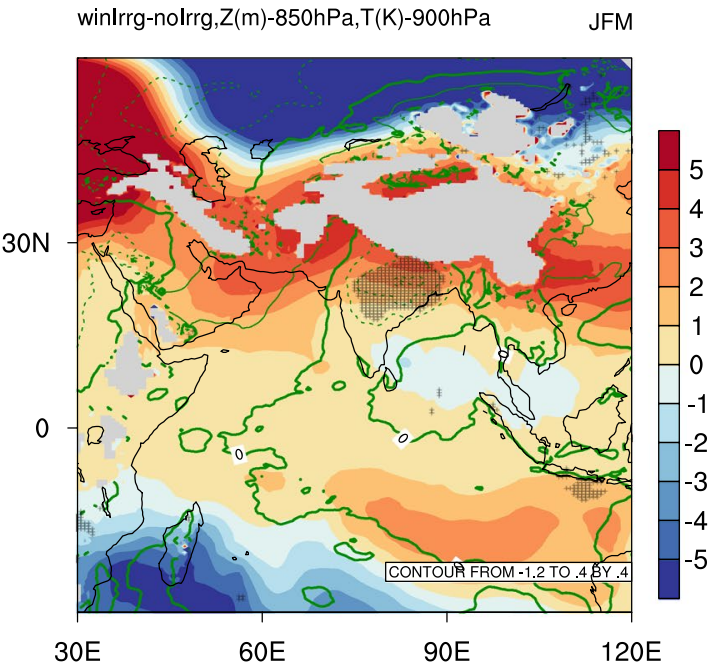

Fig. 4 Left: difference of geopotential height (m) at $850 \mathrm{hPa}$ (winIrrg-noIrrg) for January-February-March (JFM) in color contours, overlaid with difference of air temperature $(\mathrm{K})$ at $900 \mathrm{hPa}$ in green line contours, with negative anomalies in dashed lines and positive anomalies in solid lines. The line contours are from $-1.2 \mathrm{~K}$ to 0.4 $\mathrm{K}$, at an interval of $0.4 \mathrm{~K}$. Differences significant at $90 \%$ level in air

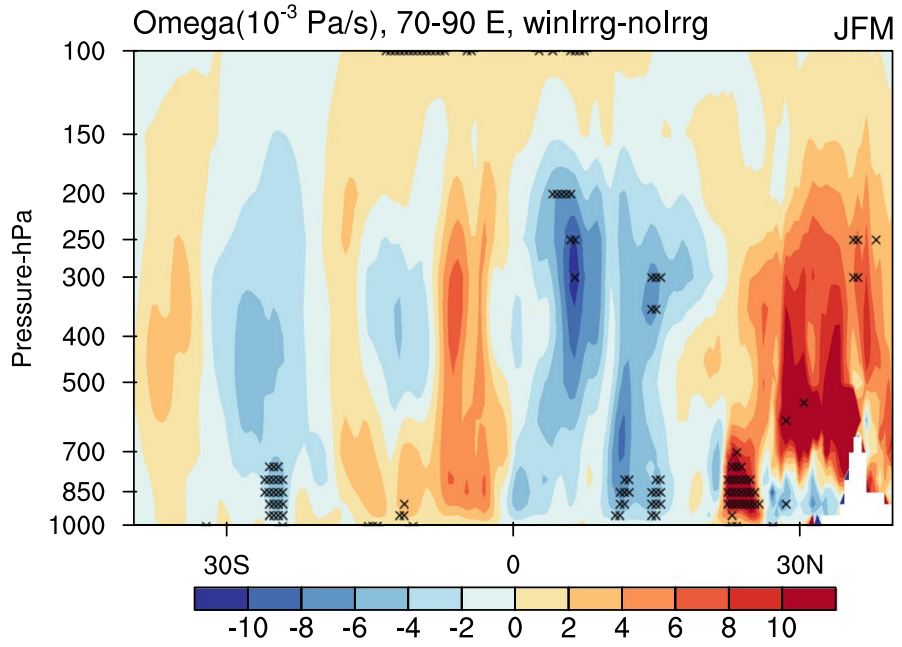

temperature are hatched. Right: difference of omega (pressure velocity in $\mathrm{Pa} \mathrm{s}^{-1}$ ) between winIrrg and noIrrg with pressure (hPa), averaged between $70^{\circ}$ and $90^{\circ} \mathrm{E}$, for JFM, shown between $40^{\circ} \mathrm{S}$ and $40^{\circ} \mathrm{N}$. Note that omega is positive downwards, which represents subsiding motion. Differences significant at $90 \%$ level are hatched (a) winlrrg-nolrrg,ps

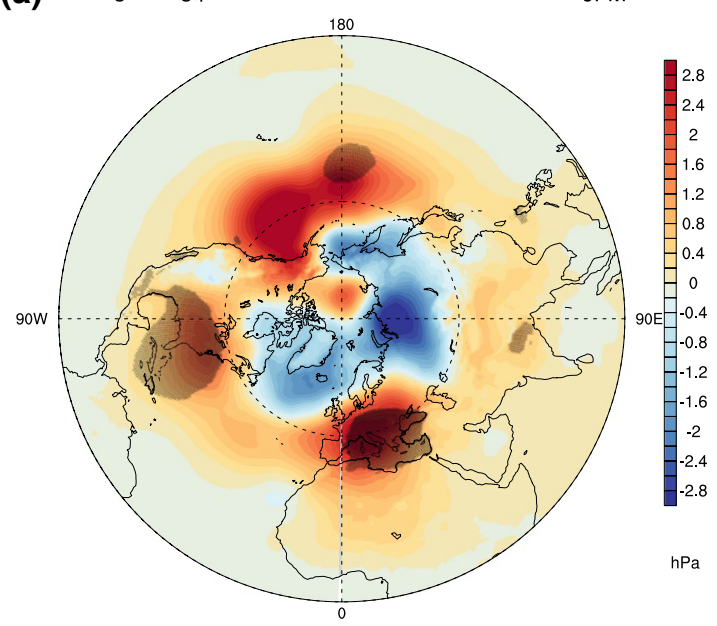

Fig. 5 a Difference in surface pressure (in $\mathrm{hPa}$ ) between winIrrg and noIrrg, for January-February-March (JFM), over the northern hemisphere. b Difference of omega (pressure velocity in $\mathrm{Pa} \mathrm{s}^{-1}$ ) with

January-March months over the northern hemisphere. Differences significant at $90 \%$ are hatched. Significant increase in mean JFM surface pressure is noted over the Indian Gangetic Plains, southern Europe, the eastern coast of North America and the north central Pacific Ocean. The increase in surface pressure over southern Europe, extending up to eastern coast of North America, and a decrease near Greenland is a pattern corresponding to a positive phase of the North Atlantic Oscillations (NAO) (Barnston and Livezey (b)

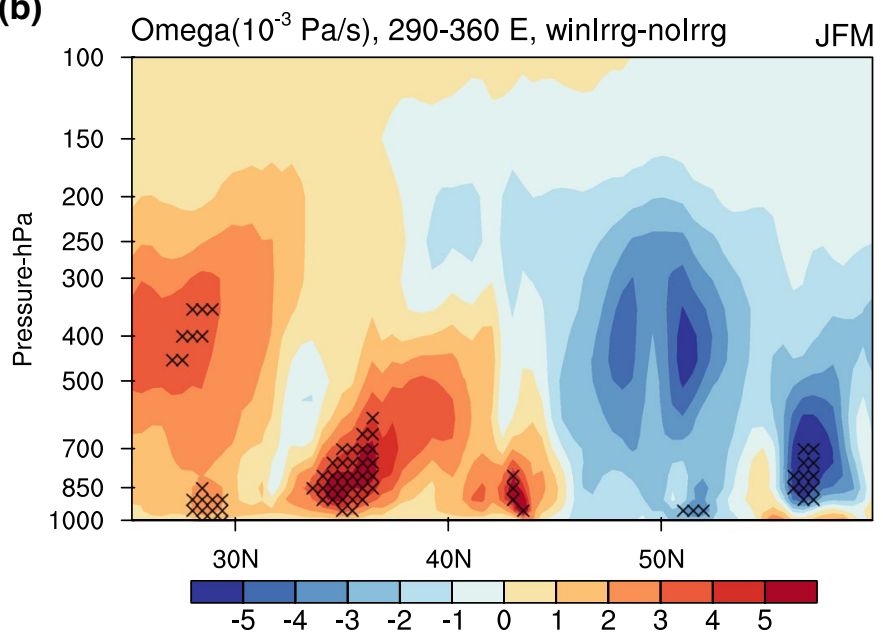

pressure $(\mathrm{hPa})$, averaged between $290^{\circ}$ and $360^{\circ} \mathrm{E}$, for JFM, shown between $25^{\circ}$ and $60^{\circ} \mathrm{N}$, that is over northern Atlantic Ocean. Differences significant at $90 \%$ are hatched

1987; Hurrell 1995; Rodwell et al. 1999; Hurrell and Deser 2009). Studies (Glowienka-Hense 1990) have shown that a positive North Atlantic oscillation phase can be induced if the mass transport is higher equator-wards of $45^{\circ} \mathrm{N}$ over the North Atlantic ocean, compared to poleward of $45^{\circ} \mathrm{N}$. In Fig. 5b, we show the difference between vertical pressure velocities along latitudes $\left(25^{\circ}-60^{\circ} \mathrm{N}\right)$ between winIrrg and noIrrg, for January-March, over North Atlantic Ocean, that is averaged between $290^{\circ}$ and $360^{\circ} \mathrm{E}$. Differences significant 
at $90 \%$ level are marked by cross. It is evident that mass anomaly is positive (that is stronger subsidence) south of $45^{\circ} \mathrm{N}$, and negative north of $45^{\circ} \mathrm{N}$, in the case of winIrrg, as compared to noIrrg. The stronger subsidence along $30^{\circ} \mathrm{N}$ can be attributed to the strengthening of the Hadley circulation owing to winter-time irrigation, as has been discussed earlier. It is worth mentioning here that many studies (Serreze et al. 2000; Hoerling et al. 2001; Visbeck et al. 2001; Delworth et al. 2016) have reported an increased propensity of the positive phase of NAO during the last few decades.

Numerous studies on NAO provide a wide view on the relationship between winter NAO index with the

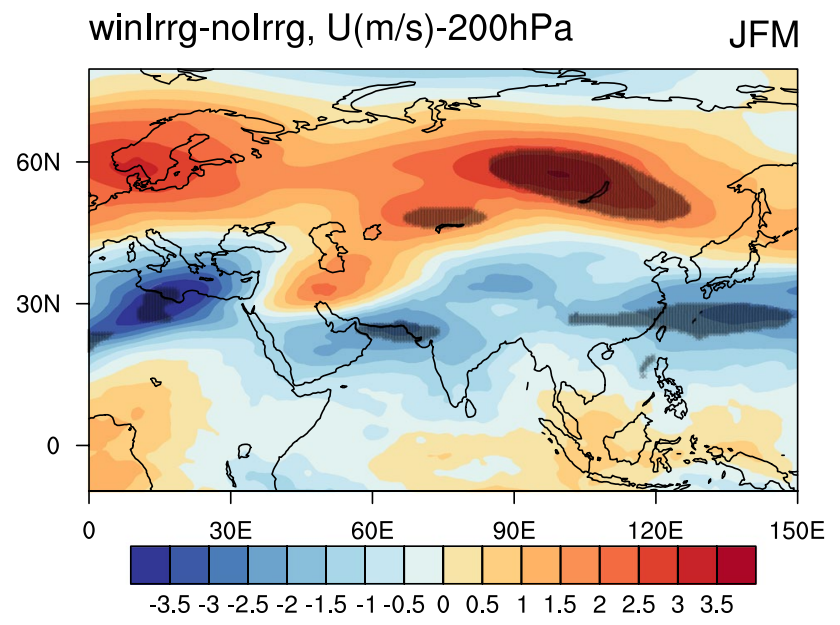

Fig. 6 Difference of upper level Zonal winds at $200 \mathrm{hPa}$ between winIrrg and noIrrg for the months of January-February-March. Differences significant at $90 \%$ are hatched

(a)

winlrrg-nolrrg

$\mathrm{T}(900 \mathrm{hPa})$

JF

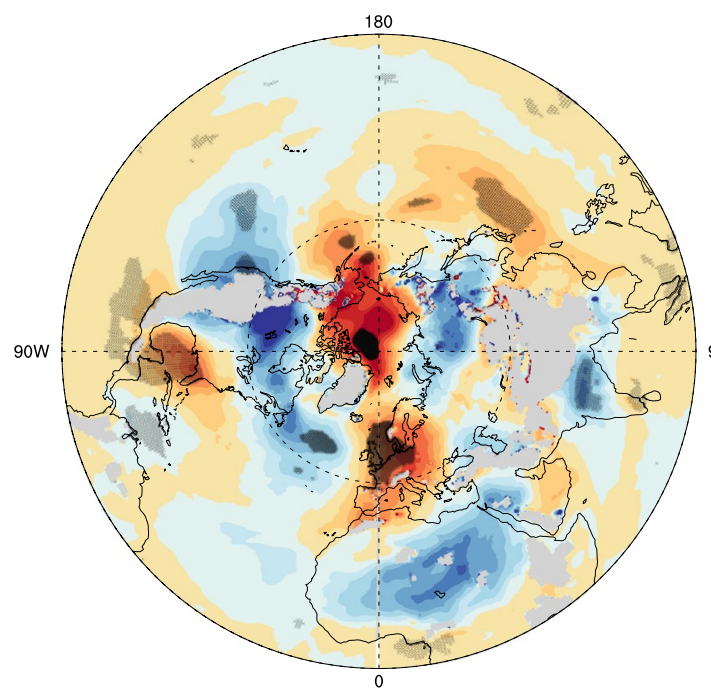

atmospheric circulation, zonal index, Eurasian snow cover, and also subsequent Indian summer monsoon (Hahn and Shukla 1976). Figure 6 shows the difference of upper level Zonal winds at $200 \mathrm{hPa}$ between winIrrg and noIrrg for January-March, where it can be noted that upper level westerlies strengthened over northern Eurasia, which corresponds to stronger zonal index ( $\mathrm{Li}$ and Wang 2003) and is related to a positive NAO phase. Differences significant at $90 \%$ are hatched. Chang et al. (2001) also showed this relationship between the positive NAO phase and upper level circulation. They mention that during positive NAO phase the interface of troughs and ridges is shifted poleward with a stronger sub-polar jet.

The effects of positive NAO phase can sustain from winter to spring season. A positive NAO phase has been related to negative snow cover anomalies and positive surface temperature changes over Eurasia (Ogi et al. 2003), and a subsequent good Indian monsoon (Hahn and Shukla 1976; Bamzai and Shukla 1999; Chang et al. 2001). Figure 7 shows the air temperature at $900 \mathrm{hPa}$ over the Northern hemisphere, for two seasons January-February (winters) and May (pre-monsoon) and differences significant at $90 \%$ are hatched. From Fig. 7a, positive temperature anomalies over western Eurasia can be noted, which are in phase with the surface pressure anomalies and are the consequence of positive NAO phase. A stronger pressure gradient between Icelandic low and Azores high (van Loon and Rogers 1978) results in stronger advection of warmer air from the Atlantic Ocean into the southern Europe, increasing the near-surface air temperature and reducing snowfall over Eurasia and central Asia. The snow depth anomalies over Eurasia can persist

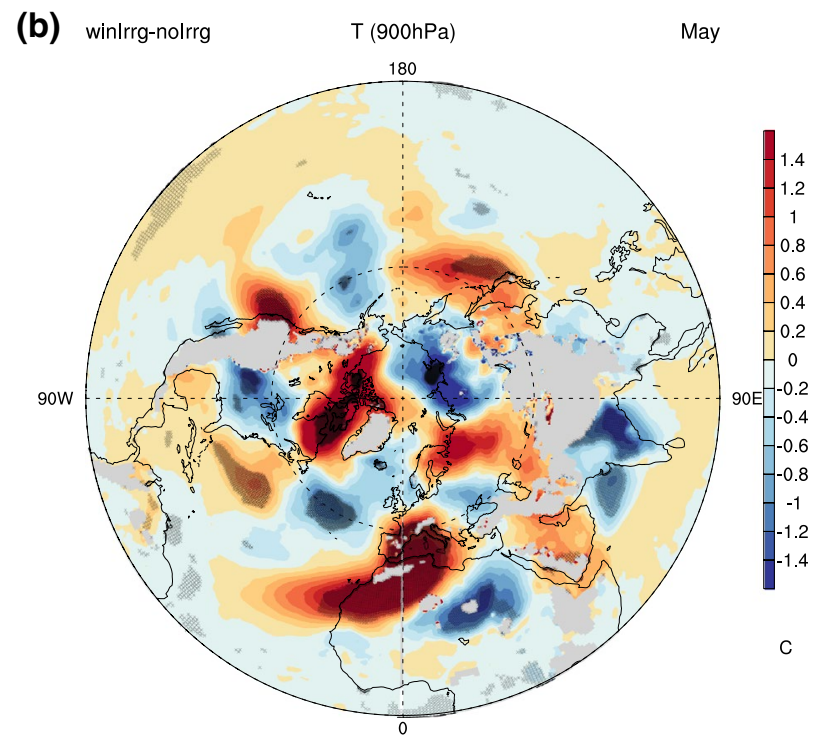

Fig. 7 Air temperature differences (in Celcius) between winIrrg and noIrrg at $900 \mathrm{hPa}$ for a January-February, b May, over northern Hemisphere. Differences significant at $90 \%$ are hatched 
from winter to spring, and thus can cause changes in springtime soil moisture and surface temperature and also surface albedo. Figure $7 \mathrm{~b}$ shows the air temperature anomalies (winIrrg-noIrrg) at $900 \mathrm{hPa}$ for May, and it can be noted that near surface temperatures are higher over southern Europe and much of west-central Asia. Thus, the effect of winter-time positive NAO phase persists up to pre-monsoon through widespread changes in the surface conditions.

\subsubsection{Effects on the pre-monsoon conditions}

Next, we examine some other pre-monsoon conditions in the case of winIrrg in comparison to noIrrg, which could be a consequence of this winter-time NAO positive phase. In Fig. 6 we noted that the upper level westerlies were stronger poleward of $45^{\circ} \mathrm{N}$, which can subsequently affect the location of troughs and ridges in mid-latitude circulations. Positive geopotential anomalies at $500 \mathrm{hPa}$ over central Asia during May, often referred as a blocking high, is a prominent feature of mid-latitude circulations and is strongly related to the early phase of the Indian monsoon and its northward propagation (Banerjee et al. 1978; Krishnamurti et al. 2010). Equator-ward penetration of this blocking high (positive geopotential anomalies at $500 \mathrm{hPa}$ ) causes westerly intrusion of mid-latitude dry air into the Indian sub-continent and negatively affects the Indian monsoon (Chakraborty and Agrawal 2017). In the left panel of Fig. 8, we have shown

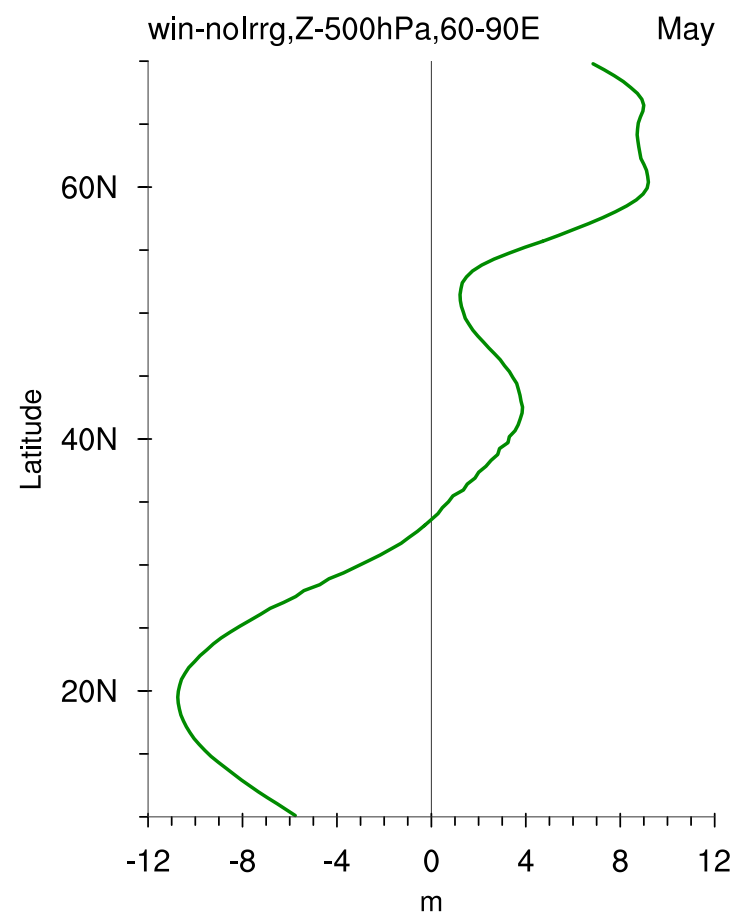

Fig. 8 Left panel: geopotential height difference at $500 \mathrm{hPa}$ between winIrrg and noIrrg, averaged between $60^{\circ}$ and $90^{\circ} \mathrm{E}$, shown between $10^{\circ}$ and $70^{\circ} \mathrm{N}$, for May. Positive geopotential height anomaly in mid- the $500 \mathrm{hPa}$ geopotential height difference between winIrrg and noIrrg, averaged between $60^{\circ}$ and $90^{\circ} \mathrm{E}$, for May. We notice that the blocking high is shifted poleward in the case of winIrrg. The right panel of Fig. 8 shows the difference of air temperature at $200 \mathrm{hPa}$ between winIrrg and noIrrg, and the differences significant at $90 \%$ are hatched. The positive air temperature anomaly over north-west India again consolidates the argument that westerly cold-air intrusion in lesser in winIrrg in May.

On analyzing the surface conditions in May for winIrrg, we find that winIrrg has much more favorable conditions for a good subsequent monsoon as compared to noIrrg. Figure 9 shows the difference of $850 \mathrm{hPa}$ geopotential height and surface pressure between winIrrg and noIrrg in May, with differences significant at $90 \%$ hatched. It can be noted that $850 \mathrm{hPa}$ geopotential height anomalies (left panel) are strongly negative over western Asia and Arabian Sea, which enhances the gradient between the equatorial Indian Ocean and western Asia. Analogous negative surface pressure anomalies can be noted in the right panel. Chakraborty and Agrawal (2017) showed through observational data analysis that such geopotential and surface pressure anomalies over western Asia in May are crucial to the onset of monsoon over central India and can be considered a harbinger of the subsequent good monsoon season, especially early onset and higher June rainfall. In agreement with these pressure anomalies, we find that the

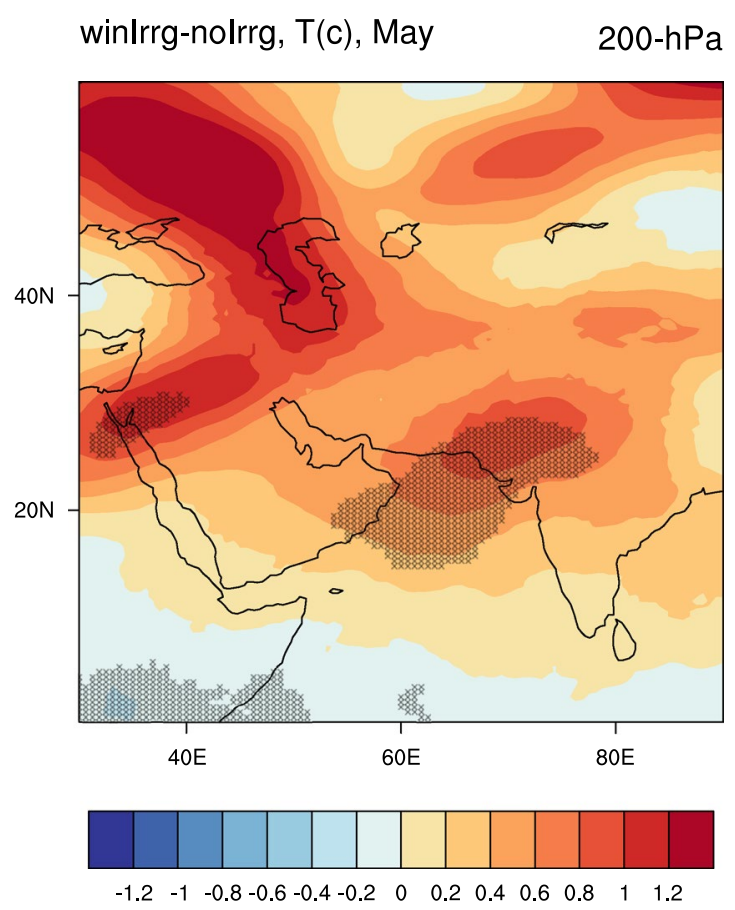

latitude over central Asia is often referred as blocking high. Right panel: Difference of air temperature at $200 \mathrm{hPa}$ between winIrrg and noIrrg in May, where differences significant at $90 \%$ are hatched 

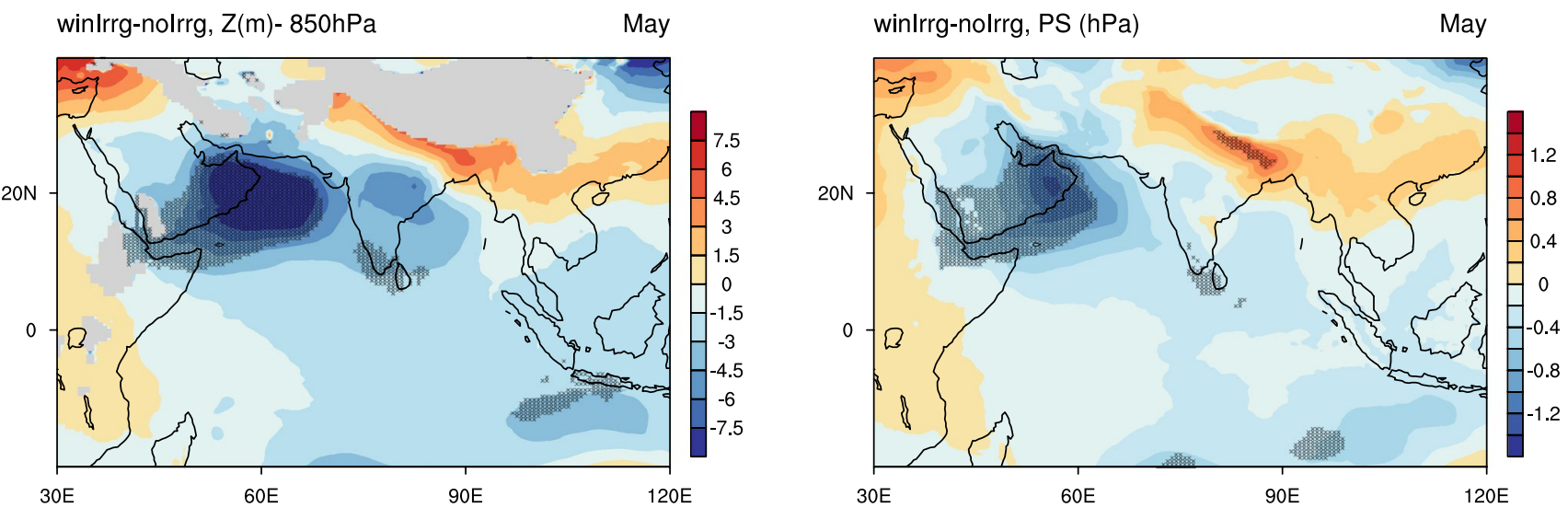

Fig. 9 Left panel: difference of geopotential height $(\mathrm{m})$ at $850 \mathrm{hPa}$ between winIrrg and noIrrg in May. Right panel: difference of surface pressure $(\mathrm{hPa})$ between winIrrg and noIrrg in May. Differences significant at $90 \%$ are hatched

low level Jet is stronger and moisture influx is higher into Indian region in winIrrg for the May and June months, and same has been presented in Fig. 10. Zonal winds at $850 \mathrm{hPa}$, averaged between $60^{\circ}$ and $70^{\circ} \mathrm{E}$, for May and June, for winIrrg (dashed line) and noIrrg (solid line), are shown in the left panel, and it can be seen that low level jet is stronger in the case of winIrrg. A stronger jet advects more moisture into the Indian region and can be seen in right panel which shows vertically integrated moisture flux crossing $70^{\circ} \mathrm{E}$ (eastward positive), both in May and June, in winIrrg. This increases the low level moist static energy over central India, decreasing the atmospheric stability, and as a consequence higher precipitation, especially during June-July in winIrrg.

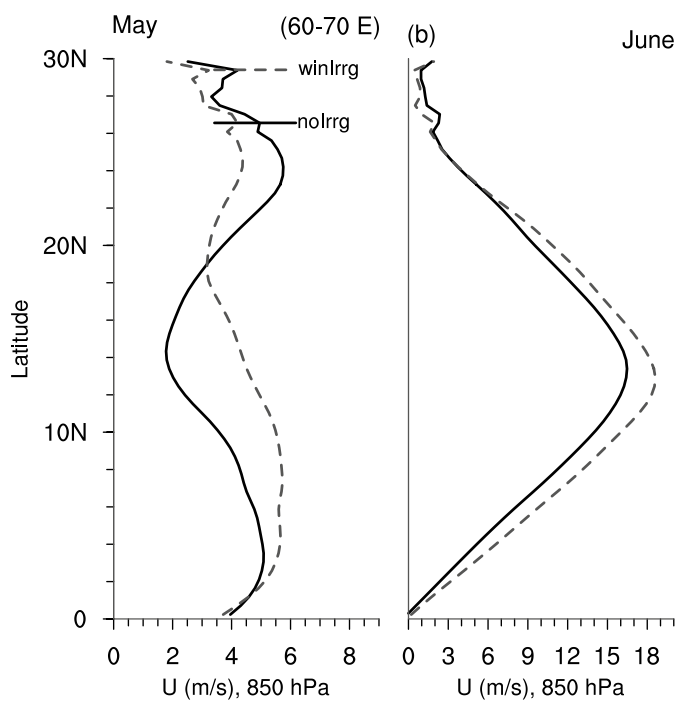

Fig. 10 Left panel: latitudinal variation (from $0^{\circ}-30^{\circ} \mathrm{N}$ ) of Zonal winds $\left(\mathrm{m} \mathrm{s}^{-1}\right)$ at $850 \mathrm{hPa}$, averaged between $60^{\circ}$ and $70^{\circ} \mathrm{E}$, for winIrrg (dashed line) and noIrrg (solid line), in a May and b June. Right

\subsubsection{Effects on intensification of the Indian monsoon}

It is worthwhile to recall here that along with increased mean seasonal rainfall in the winIrrg, as compared to noIrrg, we also noted a significant decrease in the intensity of low frequency intra-seasonal oscillations during JJAS for winIrrg over the Indian region. Since low frequency oscillations are strongly coupled to active-break cycles and northward propagation of tropical convergence zone, we inspect few more large scale variables during June-August, which have often been related to activebreak cycles, namely strength of upper level westerly jet and mid-latitude westerly cold-air intrusion (Krishnamurti et al. 2010). Near the surface, the north-south geopotential gradient is stronger and more negative over Indian region,

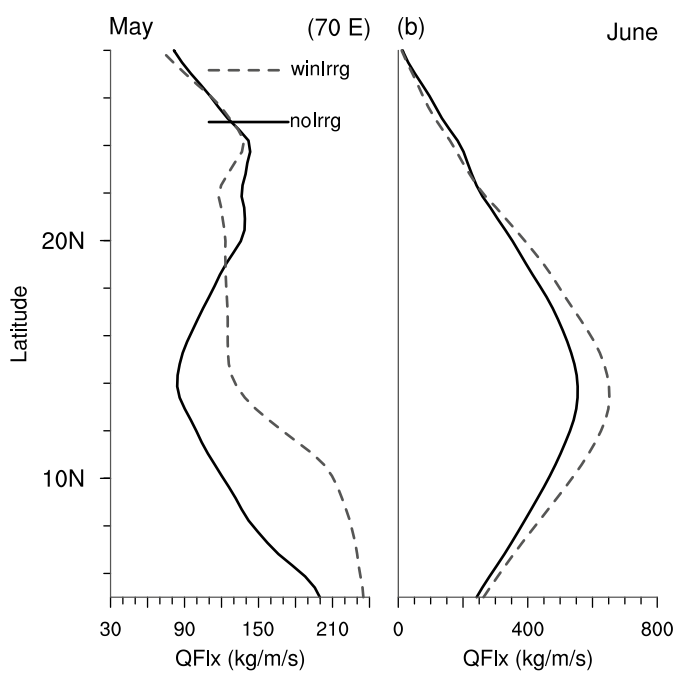

panel: latitudinal variation (from $0^{\circ}$ to $30^{\circ} \mathrm{N}$ ) of vertically integrated zonal moisture flux $\left(\mathrm{kg} \mathrm{m}^{-1} \mathrm{~s}^{-1}\right)$, crossing $70^{\circ} \mathrm{E}$ (positive eastward), for winIrrg (dashed line) and noIrrg (solid line), in a May and b June 
resulting in stronger low-level monsoonal circulation throughout the season (Figure S5). Figure 11a shows the latitudinal variation of $200 \mathrm{hPa}$ zonal winds in JJA, quantifying the strength of upper level westerlies, for winIrrg (green line) and noIrrg (black line). The zonal component of westerlies is much stronger for winIrrg between $40^{\circ}$ and $50^{\circ} \mathrm{N}$ compared to noIrrg during June-August. The stronger zonal component is categorized as a high index circulation and the meridional component is much weaker under such circumstances, which results in lesser westerly intrusion and a good Indian monsoon (Ramaswamy 1962). Figure $11 \mathrm{~b}$ shows the difference of omega (pressure velocity in $\mathrm{Pa} \mathrm{s}^{-1}$ ), averaged between $70^{\circ}$ and $90^{\circ} \mathrm{E}$, along the latitudes $\left(40^{\circ} \mathrm{S}-40^{\circ} \mathrm{N}\right)$, for June-August. Differences significant at $90 \%$ level are marked by cross. The negative anomalies between $25^{\circ}$ and $30^{\circ} \mathrm{N}$ signify lesser westerly intrusion in the case of winIrrg as compared to noIrrg. Thus, it can be inferred from here that a stronger upper level westerly jet and lesser dry air intrusion, along with a stronger monsoonal circulation, could explain the decrease in the intensity of low-frequency intra-seasonal oscillations. This could mean prolonged active spells and weaker break spells, thus increasing the mean seasonal rainfall, similar to what has been shown in many studies on intra-seasonal variability (Sperber et al. 2000; Goswami and Mohan 2001; Krishnamurthy and Shukla 2007). Lawrence and Webster (2001) and Karmakar et al. (2017a) have also reported a similar inverse relation between the low-frequency variability and seasonal mean rainfall over the Indian region and as stated earlier in Sect. 3.1, the model (CAM) is able to capture this inverse relationship (Figure S4).

\subsection{Effects of annual irrigation on the Indian monsoon}

Having analyzed the effects of winter-time irrigation on the regional and global scale and also on the Indian summer monsoon at seasonal and intra-seasonal time-scale, we extend our analysis to study the effect of adding summertime irrigation on top of winter-irrigation over the Gangetic Plains. That means, irrigation is carried throughout the year, as is practiced, and the experiment is referred as Irrg. Figure 12 a shows the spatial pattern of precipitation and $850 \mathrm{hPa}$ winds differences between Irrg and noIrrg experiments for JJAS. Precipitation differences significant at $90 \%$ and $95 \%$ level are marked by cross and stars respectively. The box highlights the Gangetic Plain region $\left(76^{\circ}-88^{\circ} \mathrm{E}\right.$, $22^{\circ}-28^{\circ} \mathrm{N}$ ). Significant reduction in precipitation can be noticed over the Gangetic Plains and an increase south of the Gangetic Plains and adjoining Bay of Bengal. A noteworthy difference exists over the west-equatorial Indian Ocean.

Figure $12 \mathrm{~b}$ shows the long-term trends in mean summer (JJAS) precipitation (in mm day ${ }^{-1}$ decade $^{-1}$ ) from observations, where precipitation data is taken from the India Meteorological Department (Rajeevan et al. 2006). Data for the period 1951-2013 has been taken for this analysis and the grids with trends significant at $90 \%$ and $95 \%$ are marked by cross and stars respectively. The spatial pattern of the observational trend is strikingly similar to the difference between Irrg and noIrrg experiments and anomalies over

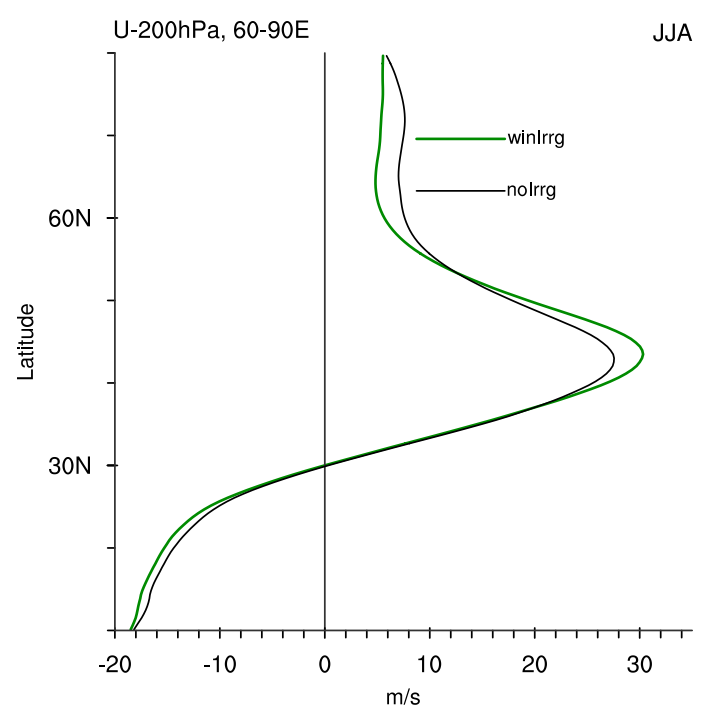

Fig. 11 Left panel: latitudinal variation (from $10^{\circ}-80^{\circ} \mathrm{N}$ ) of zonal winds $\left(\mathrm{m} \mathrm{s}^{-1}\right)$ at $200 \mathrm{hPa}$, averaged between $60^{\circ}$ and $90^{\circ} \mathrm{E}$, for winIrrg (green line) and noIrrg (black line), in June-July-August (JJA). Right panel: difference of omega (pressure velocity in $\mathrm{Pa} \mathrm{s}^{-1}$ ) with
Omega $\left(10^{-3} \mathrm{~Pa} / \mathrm{s}\right), 70-90 \mathrm{E}$, winlrrg-nolrrg JJA

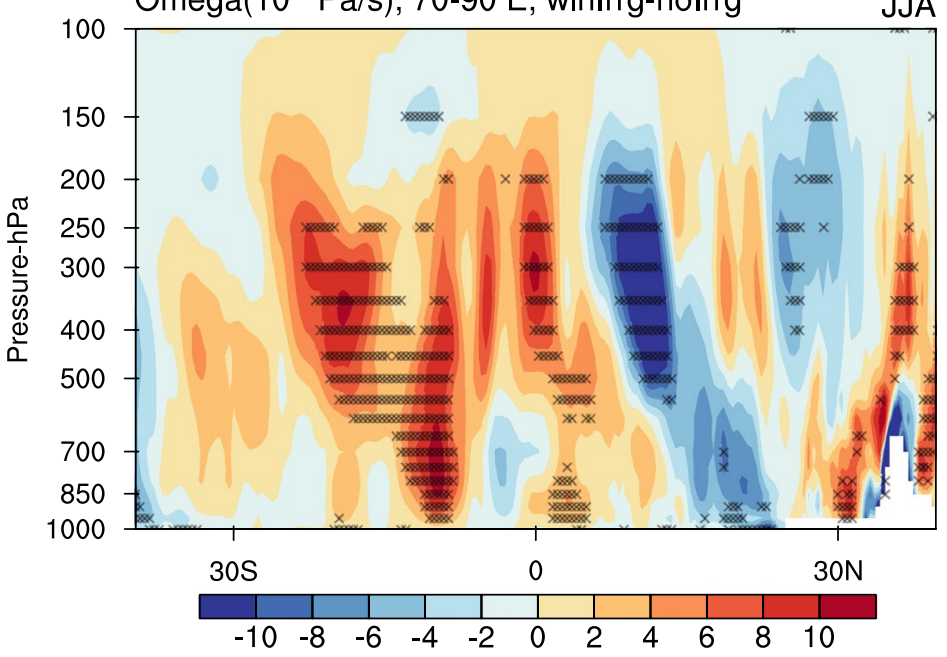

pressure (hPa) between winIrrg and noIrrg, averaged between $70^{\circ}$ and $90^{\circ} \mathrm{E}$, shown between $-40^{\circ}$ and $40^{\circ} \mathrm{N}$, for JJA. Differences significant at $90 \%$ are marked by cross 
(a) Irrg-nolrrg

JJAS

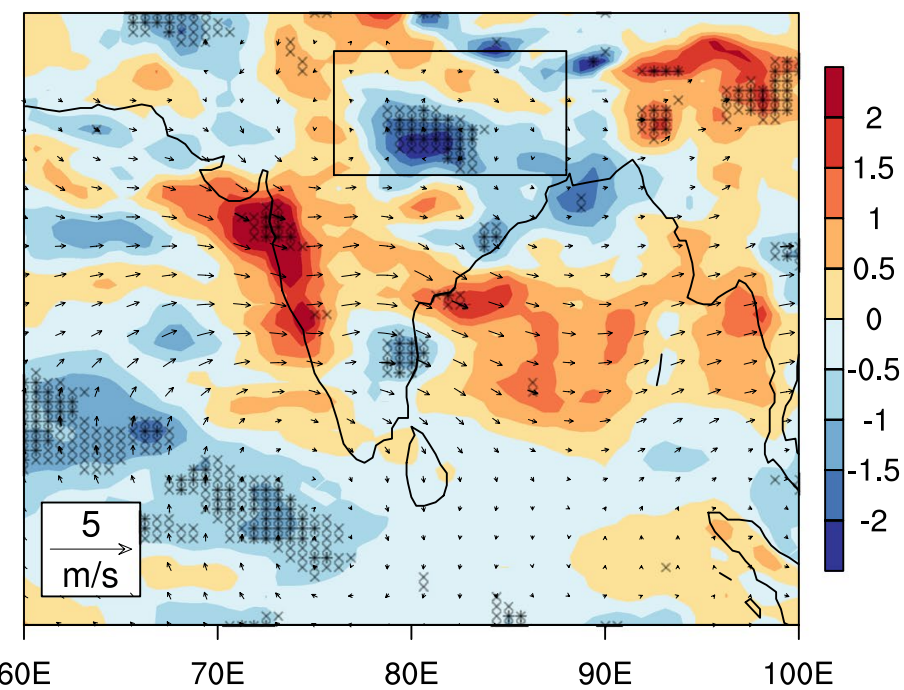

(b) IMD, JJAS

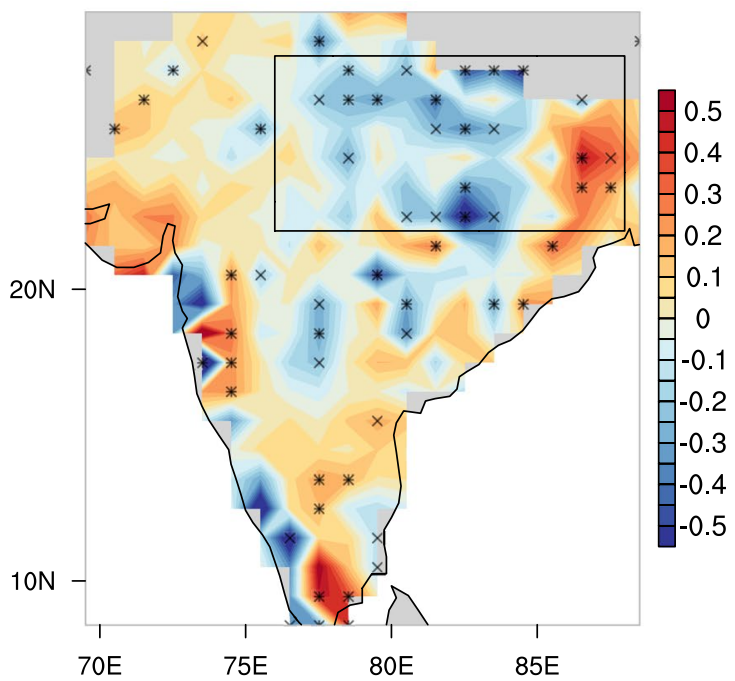

Fig. 12 Effects of annual irrigation: a Difference of simulated precipitation $\left(\mathrm{mm} \mathrm{day}^{-1}\right)$ and $850 \mathrm{hPa}$ Winds $\left(\mathrm{m} \mathrm{s}^{-1}\right)$ for Irrg and noIrrg experiments during JJAS. b Long term trends in mean summer (JJAS) precipitation (in mm day ${ }^{-1} \mathrm{decade}^{-1}$ ) from IMD observations during the period 1951-2013. Differences significant at $90 \%$ and $95 \%$ level are marked by cross and stars respectively. The box highlights the Gangetic Plain region $\left(76^{\circ}-88^{\circ} \mathrm{E}, 22^{\circ}-28^{\circ} \mathrm{N}\right)$ used in further calculations the Gangetic Plains are similar in magnitude to the observed trends (a reduction of $0.5 \mathrm{~mm}_{\text {day }}{ }^{-1}$ in a decade). Many studies have pointed out the role other factors in the weakening of the Indian monsoons, like aerosols (Bollasina et al. 2011), warming of the Indian Ocean (Roxy et al. 2015) and LULC (Paul et al. 2016). Bollasina et al. (2011) showed a very similar decrease in mean JJAS precipitation over a narrow belt in Gangetic Plains due to aerosols, and definitely, aerosols remains an important anthropogenic forcing in addition to irrigational activities in the northern plains of India. Roxy et al. (2015) related the weakening of Indian monsoon to the warming of equatorial Indian Ocean, but also discussed the possibility of warming up of the Indian Ocean due to the weakening of monsoons. We also get a small but widespread decrease in precipitation over the equatorial Indian Ocean in Irrg (Fig. 12a) which could, in turn, affect the SSTs. Paul et al. (2016) studied the effects of LULC change on the monsoon, with a large-scale conversion of forest to the crop land, and attributed reduced rainfall over central India to decrease in evapotranspiration. But the major issue is that irrigation is not considered on the crop land and irrigation can increase surface albedo and surface evaporation due to increased soil moisture. With irrigation, we find a significant precipitation reduction over the Gangetic Plains in spite of an increase in evaporation. Earlier studies (Lee et al. 2009; Douglas et al. 2009; Niyogi et al. 2010; Tuinenburg et al. 2014; Cook et al. 2015) have also attributed a similar decrease in summer precipitation over northern India to intensification of irrigation over the region and our result is consistent with them.
However, we find that this decrease in precipitation can not be simply attributed to a decreased land-sea contrast owing to irrigation, and the mechanism is much more detailed. We discuss this further in the Sect. 3.3.

Next, we show the effect of annual irrigation on the intraseasonal variability of the Indian summer monsoon. The left panel of Fig. 13 shows the difference between the LF-ISO variances of Irrg and noIrrg during JJAS, with difference significant at $90 \%$ highlighted. LF-ISO intensity decreased significantly over the Gangetic Plains and northern Bay of Bengal, which is similar to that seen earlier for winIrrg experiment in Fig. 3a. Similarly, we analyze the IMD precipitation data for long-term trends in the LF-ISO intensity, which has been filtered using the same technique as was used for filtering model output, that is multichannel singular spectrum analysis (MSSA). The right panel of Fig. 13 shows the trend in the LF-ISO intensity during JJAS, for the period 1951-2013. Note that trends are shown in $\mathrm{mm}^{2}$ day $^{-2}$ decade $^{-1}$ and the grids with a trend significant at $90 \%$ have been marked. Northern India, which includes the Gangetic Plains, shows a significant reduction in the LF-ISO variance during this period, which is again very similar to the difference between Irrg and noIrrg experiments.

One more experiment is carried out to analyze the effect of only summer-time irrigation on the seasonal rainfall, that is when irrigation is carried out only during summer months, from June to September. This experiment is referred as jjasIrrg. The changes in mean precipitation and LF-ISO intensity for JJAS are found to be very small and insignificant in 


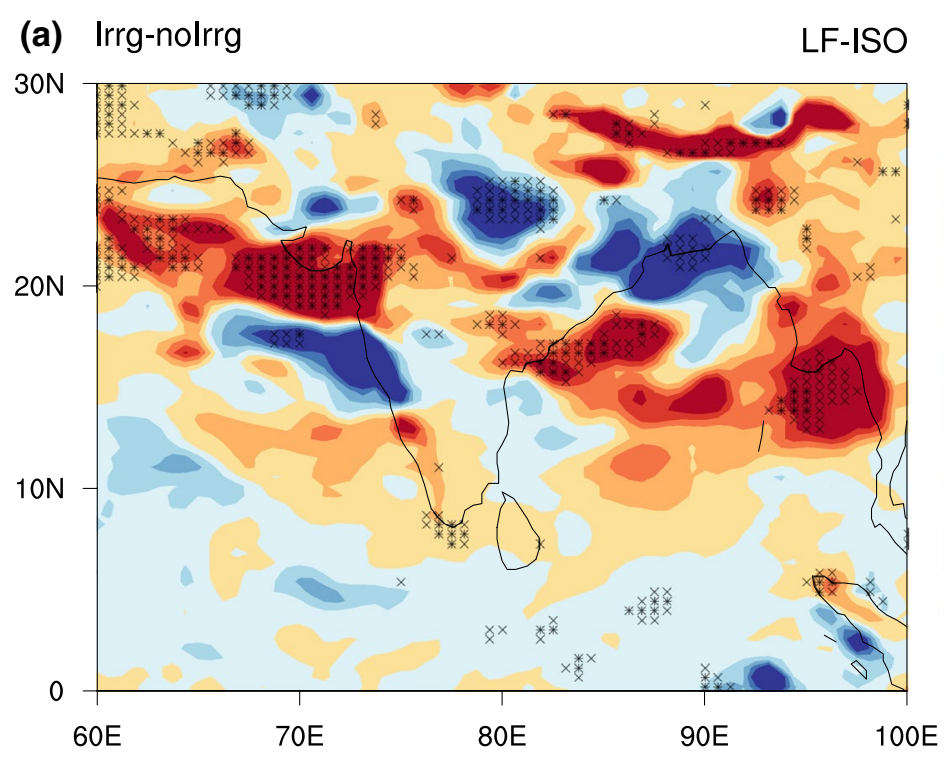
(b)
IMD, LF-ISO
$(\mathrm{mm} / \text { day })^{2} /$ decade

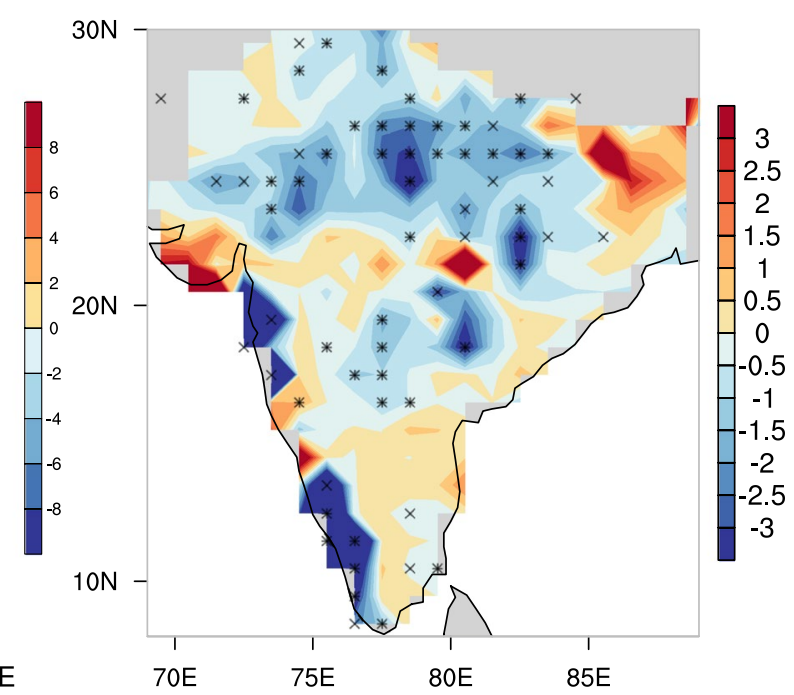

Fig. 13 a Difference between the precipitation variance $\left(\mathrm{mm}^{2}\right.$ day $\left.^{-2}\right)$ of Irrg and noIrrg (Irrg-noIrrg) during JJAS, in the low frequency domain (20-60 days time period). b Long term trends in the variance $\left(\mathrm{mm}^{2}\right.$ day $^{-2}$ decade $\left.^{-1}\right)$ of low frequency filtered precipitation

Seasonal Cycle, GP

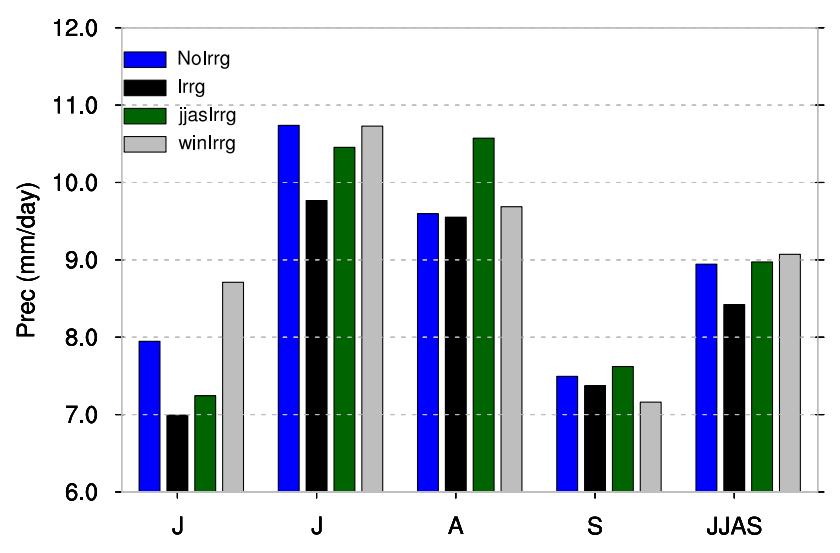

Fig. 14 Monthly mean rainfall $\left(\mathrm{mm} \mathrm{day}^{-1}\right)$ area averaged over Gangetic Plains $\left(76^{\circ}-88^{\circ} \mathrm{E}, 22^{\circ}-28^{\circ} \mathrm{N}\right)$, for the four experimentsnoIrrg (blue), Irrg (black), jjasIrrg (green), and winIrrg (gray). J J A S represent June to September respectively

the case of jjasIrrg, as compared to noIrrg (Figure S6). A band of weak negative precipitation anomaly is noted over central India, spreading across adjoining oceanic region, but these anomalies are smaller and statistically insignificant as compared to the Irrg (that is annual irrigation scenario). Thus, we can ascertain that summer-time irrigation alone is not responsible for the weakening of Indian summer monsoon, but it is the compounded effect of winter and summertime irrigation that significantly decreases rainfall over the Gangetic Plains. in summer season (JJAS), from IMD observations during the period 1951-2013. Differences significant at $90 \%$ and $95 \%$ level are marked by cross and stars respectively

Figure 14 shows the monthly mean rainfall during the summer season, area averaged over the Gangetic Plains, and a decrease of the order $0.5 \mathrm{~mm} \mathrm{day}^{-1}$ in summer precipitation can be noted only for Irrg (annual irrigation), as compared to noIrrg. Winter or summer irrigation alone do not produce such effect on local precipitation. This decrease is similar in magnitude to the decadal trend in observations. Similarly, the LF-ISO intensity, area averaged over the Gangetic Plains, decreased for the Irrg experiment, as compared to noIrrg, which is similar to the decrease seen for winIrrg. Whereas, jjasIrrg does not show any change in LF-ISO intensity over the Gangetic Plains (Figure S7).

\subsection{Mechanism of intra-seasonal variability}

Having observed a significant effect of annual irrigation on the Indian monsoon, now we examine the potential mechanism that explains the decrease in mean precipitation over the Gangetic Plains in case of annual irrigation. Here, we have examined the low-frequency oscillations (LF-ISO) cycle composites from all the experiments. The methodology used to calculate the phase angle and phase composites of the ISOs has been elaborated in Sect. 2.4.1. LF-ISO captures the precipitation anomalies fairly well in a season (Figure S8) and the LF-ISO cycle is divided into eight phases based on the phase angle. The spatial patterns of precipitation anomalies during the eight-phase LF-ISO cycle (Figure S9) is a very good representation of the characteristic northward migration of cloud bands. Since we have calculated the phase of LF-ISO cycle by taking mean over the 
Gangetic Plains, thus the phases 1-4 have positive precipitation anomalies over the Gangetic Plains, which represents an active phase of monsoon over the region. Similarly, the phases 5-8 have negative anomalies over the region, characterizing a break phase. Peninsular India and the southern Bay of Bengal have opposite anomalies as compared to the Gangetic Plains.

Now, we analyze the differences in the LF-ISO phase composites of all the experiments, over the Gangetic Plains. Figure 15a shows the mean precipitation values $\left(\mathrm{mm} \mathrm{day}^{-1}\right)$ during the 8 phases of LF-ISO composites. The black curve shows noIrrg, where a sinusoidal variation in precipitation values can be noticed, with positive phase between 1 and 4 and negative phase between 5 and 8. Precipitation distribution of jjasIrrg (dashed red curve) is very similar to noIrrg, possibly because of a negligible effect of summertime irrigation alone on the intra-seasonal variability. Next, we examine winIrrg (dashed blue curve). It can be noted that though winIrrg has a similar sinusoidal variation of precipitation, but the amplitude has reduced considerably. The cycle appears much flatter as compared to noIrrg, but centered around the same axis on y-coordinate. In simple words, precipitation intensity reduced during the positive phase and increased during the negative phase, thus maintaining the mean precipitation very close to noIrrg over the Gangetic Plain. Now, we examine the overall effect of irrigation on
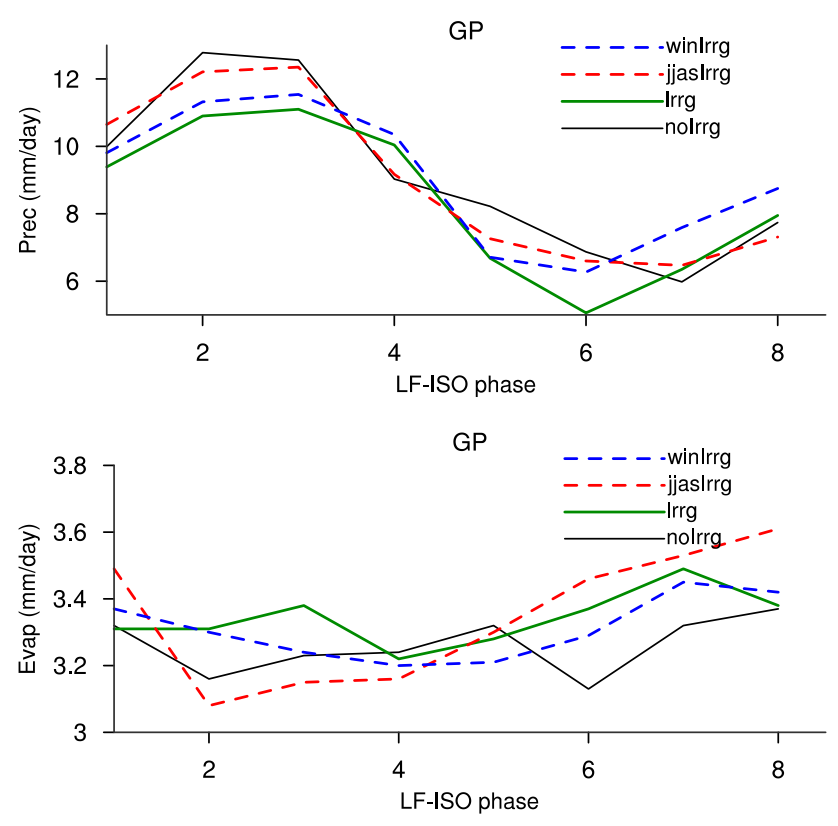

Fig. 15 Top: mean precipitation values $\left(\mathrm{mm} \mathrm{day}^{-1}\right)$ over the Gangetic Plains (GP: $76^{\circ}-88^{\circ} \mathrm{E}, 22^{\circ}-28^{\circ} \mathrm{N}$ ), during the 8 phases of LF-ISO composite. Bottom: mean evaporation values $\left(\mathrm{mm} \mathrm{day}^{-1}\right)$ during the 8 phases of LF-ISO composite. Positive phase between 1 and 4 (corresponds to phase angle between $0-\pi$ radian), and negative phase between 5 and 8 (corresponds to phase angle between $-\pi-0$ radian). The data corresponds to LF-ISO in summer months-JJAS the LF-ISO cycle from Irrg (solid green curve). The LF-ISO cycle appears very similar to winIrrg, that is much flatter due to reduced amplitude, but then precipitation reduced further in the positive phase, as well as the negative phase, and as a consequence decreased the mean precipitation over the Gangetic Plain.

It can be concluded that it is not just the local increase in soil moisture that is weakening the monsoon over northern India, but a combined effect of the decrease in LF-ISO intensity due to winter-time irrigation and the increased local soil moisture during summer monsoon owing to irrigation. The argument is further strengthened by similar analysis of mean surface evaporation (in $\mathrm{mm} \mathrm{day}^{-1}$ ) over the Gangetic Plains for the LF-ISO cycle. It can be noted from Fig. 15b that evaporation only varies between 3.1 and $3.6 \mathrm{~mm}_{\text {day }}{ }^{-1}$ (a change of nearly $0.5 \mathrm{~mm} \mathrm{day}^{-1}$ ), as compared to precipitation that varies between 6 and $12 \mathrm{~mm} \mathrm{day}^{-1}$ (a change of nearly 5-6 $\mathrm{mm} \mathrm{day}^{-1}$ ) during the LF-ISO cycle. Undoubtedly, variability in the low-level moisture convergence over the Gangetic Plains play a dominant role in the noted precipitation variability.

Figure 16 show similar variation of the low-level (at 900 $\mathrm{hPa}$ ) moist static energy, moisture, and temperature terms, area averaged over the Gangetic Plains, for the LF-ISO cycle composite. Moist static energy is given by:

$M S E=C_{p} T+L q+g z$

where $M S E$ is Moist static energy, $C_{p}$ is specific heat of dry air at constant pressure, $T$ is air temperature $(\mathrm{K}), L$ is latent heat of vaporisation, $q$ is specific humidity, $g$ is acceleration due to gravity, $z$ is height above surface. $T, q$, and $z$ are taken at $900 \mathrm{hPa}$ in these calculations.

The variation of MSE is not a simple sinusoid, but much more complex, and is mainly driven by the changes in moisture term $(L \times q)$, which are almost four times stronger than the changes in temperature term $\left(C_{p} \times T\right)$. From Fig. 16a, it can be noted that MSE of lower layer remains higher in the case of winIrrg, as compared to noIrrg, for all the LFISO phases. A similar observation can be made for Irrg, except for phase 1, and much weaker differences between phase 4 and 8 . Inspection of moisture term tells that the increased MSE in winIrrg can be attributed to increased lowlevel moisture, which is also in phase with the precipitation variations. Temperature term, however, is out of phase with both moisture and precipitation variations, with colder temperatures during the positive phase, and hotter temperatures during the negative phase of ISO-cycle.

In one final result, to substantiate our argument, we show the changes in low-level wind circulation (at $850 \mathrm{hPa}$ ) during the positive phases of LF-ISO (Sect. 2.4.1) of winIrrg and Irrg, in comparison with noIrrg, in Fig. 17. It can be noted that the convergence axis is shifted southward and also tilted along the northwest-southeast direction in the case of Irrg 

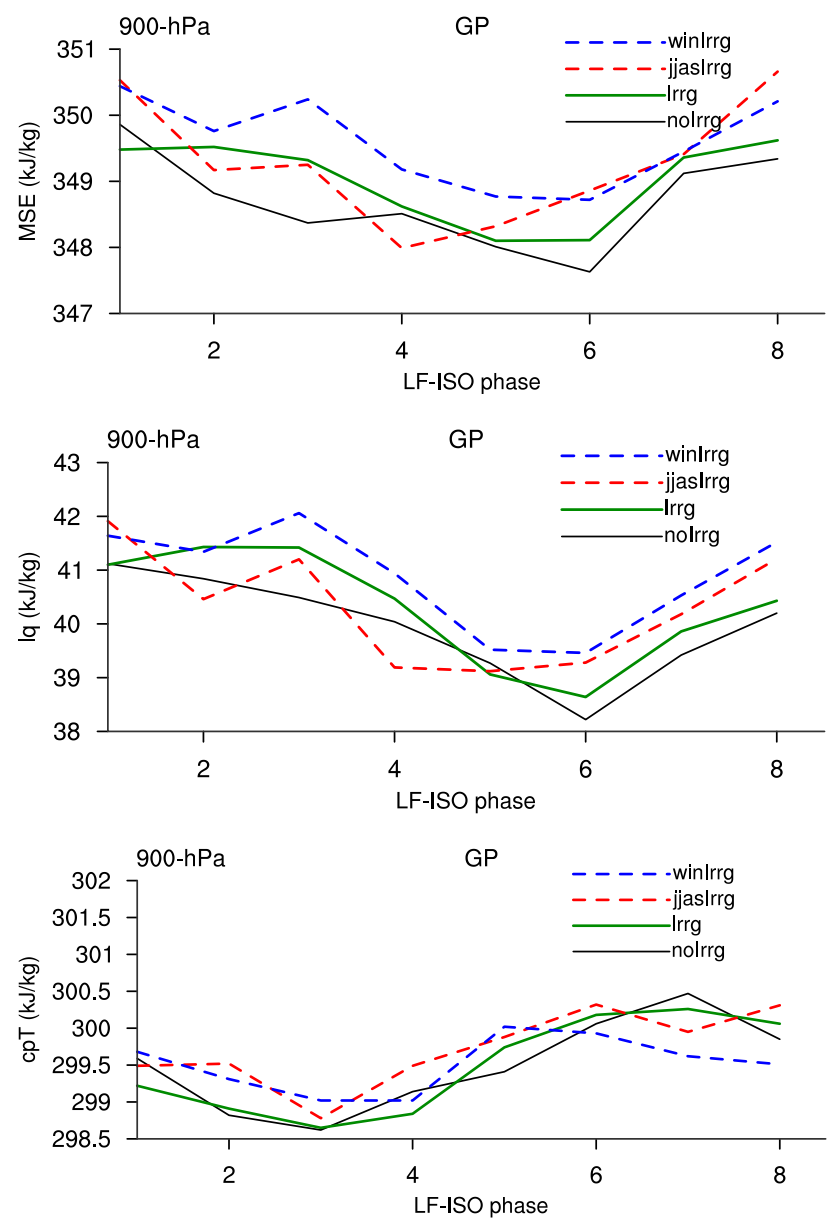

Fig. 16 Mean values over the Gangetic Plains (GP: $76^{\circ}-88^{\circ} \mathrm{E}, 22^{\circ}-$ $28^{\circ} \mathrm{N}$ ) at $900 \mathrm{hPa}$ during the 8 phases of LF-ISO (in JJAS), First: moist static energy values, Second: moisture term $(L \times q)$, Third: Temperature term $\left(C_{p} \times T\right)$. Units: $\left(\mathrm{kJ} \mathrm{kg}^{-1}\right)$
(Fig. 17a), as compared to winIrrg (Fig. 17b). Thus, in spite of higher moisture flux, explicit from low-level moisture and MSE (Fig. 16), the Gangetic Plains receive lesser rainfall due to the southward shift in the dynamic low. This shift can be attributed to enhanced local soil moisture over the Gangetic Plains in summer season due to extensive irrigational activities. It can be concluded from here that the decrease in the JJAS precipitation in the case of annual irrigation (Irrg) is not due to the weakening of monsoon circulation over the Indian region as a whole, but due to a local weakening of moisture convergence over the Gangetic Plains. In a study based on the observed precipitation data, (Chakraborty and Nanjundiah 2012) have shown a very similar result that during a weak monsoon year the axis of northward propagation of cloud bands is located equator wards of the normal position, limiting the northward penetration of cloud bands.

\section{Summary}

Increased irrigational activity over the Gangetic Plains has the potential to affect regional and remote climate. Wintertime irrigation has a strong effect on large-scale circulation pattern and also results in the intensification of the Indian summer monsoon. This is due to the fact that climatologically winter is a very cold and dry season, and agricultural activities are limited to the tropical regions only, making Indo-Gangetic Plains one of the most strongly irrigated regions of the world during this season. Addition of a huge amount of moisture to the surface due to irrigation in winters (January-March) acts as a strong forcing, decreasing the surface temperature and increasing geopotential height over the Gangetic Plains in January-March, compared to the no-irrigation scenario. This increases the gradient of geopotential over the Indian Ocean between northern and (a) Irrg-nolrrg

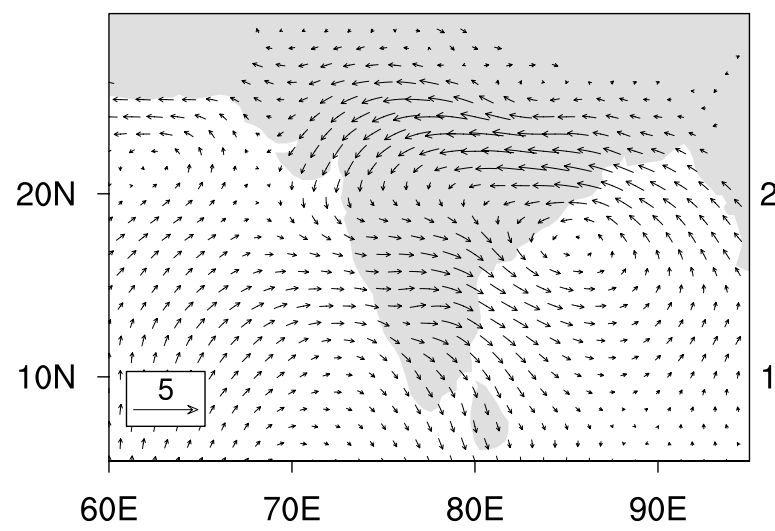

(b) winlrrg-nolrrg

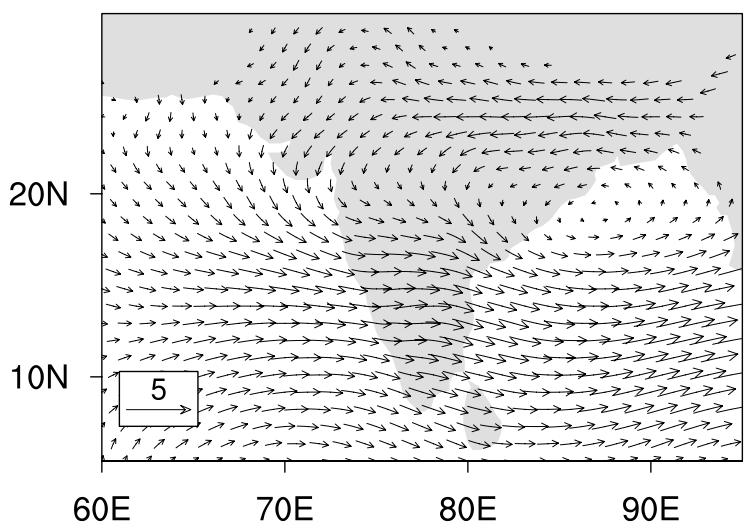

Fig. 17 Difference of mean low level winds at $850 \mathrm{hPa}$ (in $\mathrm{m} \mathrm{s}^{-1}$ ) during the active phases (that is phase angle between $\pi / 6$ and $5 \pi / 6$ ), a IrrgnoIrrg, b winIrrg-noIrrg. Summer months (JJAS) are considered 
southern hemisphere, in turn, intensifying southern hemisphere rainfall and intensifying the Hadley circulation over Indian region. A strong subsidence of air is noticed along $30^{\circ} \mathrm{N}$ as a consequence of the Hadley cell intensification and also significant surface pressure anomalies, analogous to a positive North Atlantic Oscillation (NAO) phase, is noted during the Northern Hemisphere winters. The effect of positive NAO phase persists from winter to spring through large-scale changes in surface conditions over southern and western-central Asia, which makes the pre-monsoon conditions suitable for a subsequent good monsoon over India. These large-scale changes also seem a major cause for the reduction in low-frequency intra-seasonal oscillation variability over the Indian region during monsoon season. Thus, winter-time irrigation caused intensification of the Indian monsoon and reduced the low-frequency variability, by making atmospheric conditions more conducive to convective activities during monsoons.

On the contrary, on analyzing the effect of annual irrigation over the Gangetic Plains, that is when irrigation is provided in both summer and winter months, we noted a decrease in monsoon precipitation over the Gangetic Plain in the annual irrigation scenario, as compared to the noirrigation scenario. This finding is consistent with previous studies focussing on global impact of irrigation (Tuinenburg et al. 2014; Cook et al. 2015). The spatial pattern of this decrease in mean seasonal rainfall is strikingly similar to the noted trends in observational in-situ precipitation data for the time period 1951-2013. We also identified a decrease in low-frequency variability over the Gangetic Plains in the case of annual irrigation, which is again noticeably similar to the observed trend in low-frequency variability from the in-situ precipitation data for the same time-period. The cause of this decrease in seasonal precipitation is identified to be the increase in the local soil moisture during monsoon season, which weakens the monsoon by a southward shift in the axis of low-level moisture convergence during the active phase of low-frequency oscillation. The change in low-frequency variability in the case of annual irrigation is related to winter-time irrigation. Thus, together winter and summer-time irrigation have a negative feedback on the monsoonal climate over the Gangetic Plains. Summertime irrigation alone does not seem to cause significant changes in mean rainfall or low-frequency variability during monsoon. A zonally oriented belt of weakly negative and insignificant precipitation anomalies over central India are noted with summer-irrigation alone, which is not comparable to the observed trends.

On the basis of these findings, it can be inferred with certain confidence that the negative trends in observed precipitation could be related to enhanced irrigational activities over the Gangetic Plains in the recent decades. It is worthwhile to enunciate here that parallel studies (Singh 2000;
Rodell et al. 2009) from hydrology perspective have already reported a decline in groundwater recharge level over the years and over-exploitation of groundwater for the irrigational purpose, especially in the Indian states of Haryana, Punjab and Uttar Pradesh. The demand for freshwater for irrigation is only deemed to increase in near future (Fraiture and Wichelns 2010), with an increasing pressure to increase food production for a rapidly increasing population. The negative trends in mean summer precipitation over the Gangetic Plains is thus very alarming as it could exacerbate the water crisis in the region. This imminent crisis has a huge societal, political, and economic implications. A more focused study on the prevalent irrigational and agricultural practices may offer a practical solution for combating the negative effects on climate. One such practice is irrigating at the root-zone level of crops (Kang and Zhang 2004), which has been implemented in many districts of India (Sivanappan 1994), but a detailed modeling study is required to analyze the benefits of such unconventional irrigational practices in controlling the anthropogenic effects of irrigation on the climate system.

Acknowledgements SA acknowledges the Grantham Fellowship received from Divecha Centre for Climate Change, Indian Institute of Science. AC acknowledges the MoES, India. WB and AM acknowledge funding from the UK Natural Environment Research Council (Hydroflux India project, Grant).

\section{References}

Agrawal S (2018) Impact of local and remote land-atmosphere coupling on the Indian summer monsoon. Ph.D. thesis, Indian Institute of Science

Agrawal S, Chakraborty A (2016) Role of surface hydrology in determining the seasonal cycle of Indian summer monsoon in a general circulation model. Hydrol Earth Syst Sci Discuss 2016:1-33. https ://doi.org/10.5194/hess-2016-591

Bamzai AS, Shukla J (1999) Relation between Eurasian snow cover, snow depth, and the Indian summer monsoon: an observational study. J Clim 12(10):3117-3132. https://doi.org/10.1175/15200442(1999)012<3117:RBESCS > 2.0.CO;2

Banerjee A, Sen P, Raman C (1978) On foreshadowing southwest monsoon rainfall over India with midtropospheric circulation anomaly of April. Indian J Meteorol Hydrol Geophys 29:425-431

Barnston AG, Livezey RE (1987) Classification, seasonality and persistence of low-frequency atmospheric circulation patterns. Weather Rev 115(6):1083-1126. https://doi.org/10.1175/15200493(1987)115<1083:CSAPOL>2.0.CO;2

Bollasina MA, Ming Y, Ramaswamy V (2011) Anthropogenic aerosols and the weakening of the South Asian summer monsoon. Science 334(6055):502-505. https://doi.org/10.1126/science.1204994

Chakraborty A, Agrawal S (2017) Role of west Asian surface pressure in summer monsoon onset over central India. Environ Res Lett 12(7):074,002. https://doi.org/10.1088/1748-9326/aa76ca

Chakraborty A, Nanjundiah RS (2012) Spacetime scales of northward propagation of convection during boreal summer. Mon Weather Rev 140(12):3857-3866. https://doi.org/10.1175/MWR-D-1200088.1 
Chakraborty A, Nanjundiah RS, Srinivasan J (2014) Local and remote impacts of direct aerosol forcing on Asian monsoon. Int J Climatol 34(6):2108-2121. https://doi.org/10.1002/joc.3826

Chang CP, Harr P, Ju J (2001) Possible roles of Atlantic circulations on the weakening Indian monsoon rainfallenso relationship. J Clim 14(11):2376-2380. https://doi.org/10.1175/15200442(2001)014<2376:PROACO>2.0.CO;2

Chen TC, Chen JM (1993) The 1020-day mode of the 1979 Indian monsoon: its relation with the time variation of monsoon rainfall. Mon Weather Rev 121(9):2465-2482. https://doi.org/10.1175/15200493(1993)121<2465:TDMOTI>2.0.CO;2

Cook BI, Shukla SP, Puma MJ, Nazarenko LS (2015) Irrigation as an historical climate forcing. Clim Dyn 44(5):1715-1730. https://doi. org/10.1007/s00382-014-2204-7

Dee DP, Uppala SM, Simmons AJ, Berrisford P, Poli P, Kobayashi S, Andrae U, Balmaseda MA, Balsamo G, Bauer P, Bechtold P, Beljaars ACM, van de Berg L, Bidlot J, Bormann N, Delsol C, Dragani R, Fuentes M, Geer AJ, Haimberger L, Healy SB, Hersbach H, Hlm EV, Isaksen L, Kllberg P, Khler M, Matricardi M, McNally AP, Monge-Sanz BM, Morcrette JJ, Park BK, Peubey C, de Rosnay P, Tavolato C, Thpaut JN, Vitart F (2011) The ERAinterim reanalysis: configuration and performance of the data assimilation system. Q J R Meteorol Soc 137(656):553-597. https ://doi.org/10.1002/qj.828

Delworth TL, Zeng F, Vecchi GA, Yang X, Zhang L, Zhang R (2016) The North Atlantic Oscillation as a driver of rapid climate change in the northern hemisphere. Nat Geosci 9:509. https:// doi.org/10.1038/ngeo2738

Douglas EM, Niyogi D, Frolking S, Yeluripati JB, Pielke RA, Niyogi N, Vrsmarty CJ, Mohanty UC (2006) Changes in moisture and energy fluxes due to agricultural land use and irrigation in the Indian monsoon belt. Geophys Res Lett. https://doi. org/10.1029/2006GL026550

Douglas EM, Beltran-Przekurat A, Niyogi D, RAP Sr, Vorosmarty CJ (2009) The impact of agricultural intensification and irrigation on land-atmosphere interactions and Indian monsoon precipitationa mesoscale modeling perspective. Glob Planet Change 67:117128. https://doi.org/10.1016/j.gloplacha.2008.12.007

Fraiture C, Wichelns D (2010) Satisfying future water demands for agriculture. Agric Water Manag 97(4):502-511. https://doi. org/10.1016/j.agwat.2009.08.008

Gadgil S, Gadgil S (2006) The Indian monsoon, GDP and agriculture. Econ Polit Wkly 41(47):4887-4895

Ghil M, Allen MR, Dettinger MD, Ide K, Kondrashov D, Mann ME, Robertson AW, Saunders A, Tian Y, Varadi F, Yiou P (2002) Advanced spectral methods for climatic time series. Rev Geophys. https://doi.org/10.1029/2000RG000092

Glowienka-Hense R (1990) The North Atlantic Oscillation in the Atlantic-European SLP. Tellus A Dyn Meteorol Oceanogr 42(5):497-507. https://doi.org/10.3402/tellusa.v42i5.11893

Goswami BN, Mohan RSA (2001) Intraseasonal oscillations and interannual variability of the Indian summer monsoon. J Clim 14(6):1180-1198. https://doi.org/10.1175/15200442(2001)014<1180:IOAIVO>2.0.CO;2

Goswami BN, Venugopal V, Sengupta D, Madhusoodanan MS, Xavier PK (2006) Increasing trend of extreme rain events over India in a warming environment. Science 314(5804):1442-1445. https:// doi.org/10.1126/science. 1132027

Guhathakurta P, Revadekar J (2017) Observed variability and longterm trends of rainfall over India. In: Rajeevan M, Nayak S (eds) Observed climate variability and change over the Indian region. Springer Geology, Springer, Singapore

Hahn DG, Shukla J (1976) An apparent relationship between Eurasian snow cover and Indian monsoon rainfall. J Atmos Scie 33(12):2461-2462. https://doi.org/10.1175/15200469(1976)033<2461:AARBES>2.0.CO;2
Hoerling MP, Hurrell JW, Xu T (2001) Tropical origins for recent North Atlantic climate change. Science 292(5514):90-92. https ://doi.org/10.1126/science.1058582

Huffman GJ, Bolvin DT, Nelkin EJ, Wolff DB, Adler RF, Gu G, Hong Y, Bowman KP, Stocker EF (2007) The TRMM multisatellite precipitation analysis (TMPA): quasi-global, multiyear, combined-sensor precipitation estimates at fine scales. J Hydrometeorol 8(1):38-55. https://doi.org/10.1175/JHM560.1

Hurrell JW (1995) Decadal trends in the North Atlantic Oscillation: regional temperatures and precipitation. Science 269(5224):676-679. https://doi.org/10.1126/scien ce. 269.5224 .676

Hurrell JW, Deser C (2009) North Atlantic climate variability: the role of the North Atlantic Oscillation. J Mar Syst 78(1):28-41. https://doi.org/10.1016/j.jmarsys.2008.11.026

Islam Su, Tang Y, Jackson PL (2013) Asian monsoon simulations by community climate models CAM4 and CCSM4. Clim Dyn 41(9):2617-2642. https://doi.org/10.1007/s00382-013-1752-6

Jeuken ABM, Siegmund PC, Heijboer LC, Feichter J, Bengtsson L (1996) On the potential of assimilating meteorological analyses in a global climate model for the purpose of model validation. J Geophys Res Atmos 101(D12):16,939-16,950. https://doi. org/10.1029/96JD01218

Kang S, Zhang J (2004) Controlled alternate partial root-zone irrigation: its physiological consequences and impact on water use efficiency. J Exp Bot 55(407):2437-2446. https://doi. org/10.1093/jxb/erh249

Kang IS, Jin K, Wang B, Lau KM, Shukla J, Krishnamurthy V, Schubert S, Wailser D, Stern W, Kitoh A, Meehl G, Kanamitsu M, Galin V, Satyan V, Park CK, Liu Y (2002) Intercomparison of the climatological variations of Asian summer monsoon precipitation simulated by 10 GCMs. Clim Dyn 19(5):383-395. https ://doi.org/10.1007/s00382-002-0245-9

Karmakar N, Chakraborty A, Nanjundiah RS (2015) Decreasing intensity of monsoon low-frequency intraseasonal variability over India. Environ Res Lett 10(5):054,018

Karmakar N, Chakraborty A, Nanjundiah R (2017a) Spacetime evolution of the low- and high-frequency intraseasonal modes of the Indian summer monsoon. Mon Weather Rev 145(2):413435. https://doi.org/10.1175/MWR-D-16-0075.1

Karmakar N, Chakraborty A, Nanjundiah RS (2017b) Increased sporadic extremes decrease the intraseasonal variability in the Indian summer monsoon rainfall. Sci Rep 7(1):2045-2322. https ://doi.org/10.1038/s41598-017-07529-6

Koster RD, Dirmeyer PA, Guo Z, Bonan G, Chan E, Cox P, Gordon CT, Kanae S, Kowalczyk E, Lawrence D, Liu P, Lu CH, Malyshev S, McAvaney B, Mitchell K, Mocko D, Oki T, Oleson K, Pitman A, Sud YC, Taylor CM, Verseghy D, Vasic R, Xue Y, Yamada T (2004) Regions of strong coupling between soil moisture and precipitation. Science 305(5687):1138-1140. https ://doi.org/10.1126/science.1100217

Krishnamurthy V, Shukla J (2007) Intraseasonal and seasonally persisting patterns of Indian monsoon rainfall. J Clim 20(1):3-20. https://doi.org/10.1175/JCLI3981.1

Krishnamurthy CKB, Lall U, Kwon HH (2009) Changing frequency and intensity of rainfall extremes over India from 1951 to 2003. J Clim 22(18):4737-4746. https://doi.org/10.1175/2009JCLI28 96.1

Krishnamurti TN, Bhalme HN (1976) Oscillations of a monsoon system. Part I. Observational aspects. J Atmos Sci 33(10):1937-1954. https://doi.org/10.1175/1520-0469(1976)033<1937:OOAMS $\mathrm{P}>2.0 . \mathrm{CO} ; 2$

Krishnamurti TN, Thomas a, Simon A, Kumar V (2010) Desert air incursions, an overlooked aspect, for the dry spells of the Indian summer monsoon. J Atmos Sci 67(10):3423-3441. https://doi. org/10.1175/2010JAS3440.1 
Kulkarni A (2012) Weakening of Indian summer monsoon rainfall in warming environment. Theor Appl Climatol 109(3):447-459. https://doi.org/10.1007/s00704-012-0591-4

Lawrence DM, Webster PJ (2001) Interannual variations of the intraseasonal oscillation in the South Asian summer monsoon region. J Clim 14(13):2910-2922. https://doi.org/10.1175/15200442(2001)014<2910:IVOTIO>2.0.CO;2

Lee E, Chase TN, Rajagopalan B, Barry RG, Biggs TW, Lawrence PJ (2009) Effects of irrigation and vegetation activity on early Indian summer monsoon variability. Int J Climatol 29(4):573-581. https ://doi.org/10.1002/joc.1721

Lee E, Sacks WJ, Chase TN, Foley JA (2011) Simulated impacts of irrigation on the atmospheric circulation over Asia. J Geophys Res Atmos. https://doi.org/10.1029/2010JD014740

Li J, Wang JXL (2003) A modified zonal index and its physical sense. Geophys Res Lett. https://doi.org/10.1029/2003GL017441

Meehl GA, Arblaster JM, Collins WD (2008) Effects of black carbon aerosols on the Indian monsoon. J Clim 21(12):2869-2882. https ://doi.org/10.1175/2007JCLI1777.1

Meehl GA, Arblaster JM, Caron JM, Annamalai H, Jochum M, Chakraborty A, Murtugudde R (2012) Monsoon regimes and processes in CCSM4. Part I: the Asian-Australian monsoon. J Clim 25(8):2583-2608. https://doi.org/10.1175/JCLI-D-11-00184.1

Moron V, Vautard R, Ghil M (1998) Trends, interdecadal and interannual oscillations in global sea-surface temperatures. Clim Dyn 14(7):545-569. https://doi.org/10.1007/s003820050241

Moulds S (2016) Toward integrated modelling systems to assess vulnerability of water resources under environmental change. Ph.D. thesis, Imperial College London

Murakami M (1976) Analysis of summer monsoon fluctuations over India. J Meteorol Soc Jpn Ser II 54(1):15-31. https://doi. org/10.2151/jmsj1965.54.1_15

Naidu CV, Durgalakshmi K, Krishna KM, Rao SR, Satyanarayana GC, Lakshminarayana P, Rao LM (2010) Is summer monsoon rainfall decreasing over India in the global warming era? J Geophys Res Atmos. https://doi.org/10.1029/2008JD011288

Naidu C, Raju AD, Satyanarayana G, Kumar PV, Chiranjeevi G, Suchitra P (2015) An observational evidence of decrease in Indian summer monsoon rainfall in the recent three decades of global warming era. Glob Planet Change 127:91-102. https://doi. org/10.1016/j.gloplacha.2015.01.010

Niyogi D, Kishtawal C, Tripathi S, Govindaraju RS (2010) Observational evidence that agricultural intensification and land use change may be reducing the Indian summer monsoon rainfall. Water Resour Res. https://doi.org/10.1029/2008WR007082

Ogi M, Tachibana Y, Yamazaki K (2003) Impact of the wintertime North Atlantic Oscillation (NAO) on the summertime atmospheric circulation. Geophys Res Lett 30(13):1704. https://doi. org/10.1029/2003GL017280

Pattanaik DR (2007) Analysis of rainfall over different homogeneous regions of India in relation to variability in westward movement frequency of monsoon depressions. Nat Hazards 40(3):635-646. https://doi.org/10.1007/s11069-006-9014-0

Patwardhan SK, Bhalme HN (2001) A study of cyclonic disturbances over India and the adjacent ocean. Int J Climatol 21:527-534. https://doi.org/10.1002/joc.615

Paul S, Ghosh S, Oglesby R, Pathak A, Chandrasekharan A, Ramsankaran R (2016) Weakening of Indian summer monsoon rainfall due to changes in land use land cover. Sci Rep. https://doi. org/10.1038/srep32177

Puma MJ, Cook BI (2010) Effects of irrigation on global climate during the 20th century. J Geophys Res Atmos 115(D16):d16120. https://doi.org/10.1029/2010JD014122

Rajeevan M, Bhate J, Kale JD, Lal B (2006) High resolution daily gridded rainfall data for the Indian region: analysis of break and active monsoon spells. Curr Sci 91(3):296-306
Rajeevan M, Bhate J, Jaswal AK (2008) Analysis of variability and trends of extreme rainfall events over India using 104 years of gridded daily rainfall data. Geophys Res Lett 35(18):118707. https://doi.org/10.1029/2008GL035143

Ramaswamy C (1962) Breaks in the Indian summer monsoon as a phenomenon of interaction between the easterly and the subtropical westerly jet streams. Tellus 14(3):337-349. https://doi. org/10.3402/tellusa.v14i3.9560

Rodell M, Velicogna I, Famiglietti JS (2009) Satellite-based estimates of groundwater depletion in India. Nature 460:999-1002. https://doi.org/10.1038/nature08238

Rodwell MJ, Rowell DP, Folland CK (1999) Oceanic forcing of the wintertime North Atlantic Oscillation and European climate. Nature 398:320. https://doi.org/10.1038/18648

Roxy MK, Ritika K, Terray P, Murtugudde R, Ashok K, Goswami BN (2015) Drying of Indian subcontinent by rapid Indian ocean warming and a weakening land-sea thermal gradient. Nat Commun. https://doi.org/10.1038/ncomms8423

Sabeerali CT, Ramu Dandi A, Dhakate A, Salunke K, Mahapatra S, Rao SA (2013) Simulation of boreal summer intraseasonal oscillations in the latest CMIP5 coupled GCMS. J Geophys Res Atmos 118(10):4401-4420. https://doi.org/10.1002/jgrd.50403

Sacks WJ, Cook BI, Buenning N, Levis S, Helkowski JH (2009) Effects of global irrigation on the near-surface climate. Clim Dyn 33(2):159-175. https://doi.org/10.1007/s00382-008-0445-z

Saha KR, Mooley DA, Saha S (1979) The Indian monsoon and its economic impact. GeoJournal 3(2):171-178. https://doi. org/10.1007/BF00257706

Serreze MC, Walsh JE, Chapin FS, Osterkamp T, Dyurgerov M, Romanovsky V, Oechel WC, Morison J, Zhang T, Barry RG (2000) Observational evidence of recent change in the northern high-latitude environment. Clim Change 46(1):159-207. https ://doi.org/10.1023/A:1005504031923

Shukla SP, Puma MJ, Cook BI (2014) The response of the South Asian summer monsoon circulation to intensified irrigation in global climate model simulations. Clim Dyn 42:21-36. https:// doi.org/10.1007/s00382-013-1786-9

Siebert S, Burke J, Faures JM, Frenken K, Hoogeveen J, Döll P, Portmann FT (2010) Groundwater use for irrigation a global inventory. Hydrol Earth Syst Sci 14(10):1863-1880. https://doi. org/10.5194/hess-14-1863-2010

Sikka DR, Gadgil S (1980) On the maximum cloud zone and the ITCZ over Indian, longitudes during the southwest monsoon. Mon Weather Rev 108(11):1840-1853. https://doi. org/10.1175/1520-0493(1980)108<1840:OTMCZA > 2.0.CO;2

Singh R (2000) Environmental consequences of agricultural development: a case study from the green revolution state of Haryana, India. Agric Ecosyst Environ 82(1):97-103. https://doi. org/10.1016/S0167-8809(00)00219-X

Sinha A, Kathayat G, Cheng H, Breitenbach SF, Berkelhammer M, Mudelsee M, Biswas J, Edwards R (2015) Trends and oscillations in the Indian summer monsoon rainfall over the last two millennia. Nat Commun 6:6309. https://doi.org/10.1038/ ncomms 7309

Sivanappan RK (1994) Prospects of micro-irrigation in India. Irrigat Drain Syst 8(1):49-58. https://doi.org/10.1007/BF00880798

Sperber KR, Slingo JM, Annamalai H (2000) Predictability and the relationship between subseasonal and interannual variability during the Asian summer monsoon. Q J R Meteorol Soc 126(568):2545-2574. https://doi.org/10.1002/qj.49712656810

Telford PJ, Braesicke P, Morgenstern O, Pyle JA (2008) Technical note: description and assessment of a nudged version of the new dynamics unified model. Atmos Chem Phys 8(6):1701-1712. https://doi. org/10.5194/acp-8-1701-2008

Thiery W, Davin EL, Lawrence DM, Hirsch AL, Hauser M, Seneviratne SI (2017) Present-day irrigation mitigates heat 
extremes. J Geophys Res Atmos 122(3):1403-1422. https://doi. org/10.1002/2016JD025740

Tuinenburg OA, Hutjes RWA, Stacke T, Wiltshire A, Lucas-Picher $P$ (2014) Effects of irrigation in India on the atmospheric water budget. J Hydrometeorol 15(3):1028-1050. https://doi. org/10.1175/JHM-D-13-078.1

Turner AG, Annamalai H (2012) Climate change and the South Asian summer monsoon. Nat Clim Change 2:587. https://doi. org/10.1038/nclimate 1495

van Loon H, Rogers JC (1978) The seesaw in winter temperatures between Greenland and northern Europe. Part I: general description. Mon Weather Rev 106(3):296-310. https://doi. org/10.1175/1520-0493(1978)106<0296:TSIWTB > 2.0.CO;2

Visbeck MH, Hurrell JW, Polvani L, Cullen HM (2001) The North Atlantic Oscillation: past, present, and future. Proc Nat Acad Sci 98(23):12,876-12,877. https://doi.org/10.1073/pnas.231391598
Vishnu S, Francis PA, Shenoi SSC, Ramakrishna SSVS (2016) On the decreasing trend of the number of monsoon depressions in the Bay of Bengal. Environ Res Lett 11:014,011. https://doi. org/10.1088/1748-9326/11/1/014011

Wey HW, Lo MH, Lee SY, Yu JY, Hsu HH (2015) Potential impacts of wintertime soil moisture anomalies from agricultural irrigation at low latitudes on regional and global climates. Geophys Res Lett 42:8605-8614. https://doi.org/10.1002/2015GL065883

Yasunari T (1979) Cloudiness fluctuations associated with the northern hemisphere summer monsoon. J Meteorol Soc Jpn 57:227-242

Publisher's Note Springer Nature remains neutral with regard to jurisdictional claims in published maps and institutional affiliations. 